\title{
Numerical analysis of symmetrical and asymmetrical reinforced concrete flat slabs - an integrated slab/ column analysis
}

\section{Análise numérica de lajes planas simétricas e assimétricas em concreto armado - análise integrada laje/pilar}
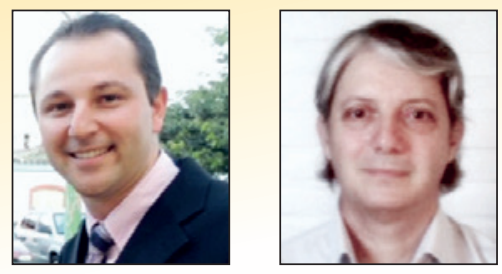

A. PUEL a puel@ifsc.edu.br

D. D. LORIGGIO daniel.loriggio@ufsc.br

\begin{abstract}
This paper studies the modeling of symmetric and asymmetric flat slabs, presenting alternatives to the problem of singularity encountered when the slab is modeled considering columns as local support. A model that includes the integrated slab $\mathrm{x}$ column analysis was proposed, distributing the column reactions under the slab. The procedure used transforms the bending moment and column axial force in a distributed load, which will be applied to the slab in the opposite direction of gravitational loads. Thus, the bending moment diagram gets smooth in the punching region with a considerable reduction of values, being very little sensible to the variation of used mesh. About the column, it was not seen any significant difference in the axial force, although the same haven't occurred with the bending moments results. The final part of the work uses geoprocessing programs for a three-dimensional view of bending moments, allowing a new comprehension the behavior of these internal forces in the entire slab.
\end{abstract}

Keywords: flat slabs, reinforced concrete, FEM, singularity.

\section{Resumo}

Este trabalho estuda a modelagem de lajes planas simétricas e assimétricas, apresentando alternativas para o problema da singularidade ocorrido quando se modela a laje considerando os pilares como apoio pontual. Foi proposto um modelo que contempla a análise integrada Laje $x$ Pilar, distribuindo a reação do pilar na laje. O procedimento utilizado consiste em transformar o momento fletor e o esforço normal do pilar em um carregamento distribuído, que será adicionado na laje como carregamento no sentido contrário à ação das cargas gravitacionais. Com isso, tem-se um arredondamento do diagrama de momento fletor da laje na região do pilar puncionado com uma considerável redução dos valores, sendo pouco sensível à variação da malha utilizada. Em relação ao pilar, o esforço normal não apresentou diferenças significativas, porém o mesmo não ocorreu com o momento fletor. A parte final do artigo utiliza programas de geoprocessamento para uma visualização tridimensional dos momentos fletores, permitindo uma nova compreensão do comportamento desses esforços ao longo de toda a laje.

Palavras-chave: lajes planas, concreto armado, método dos elementos finitos, singularidade 


\section{Introduction}

The flat slabs are an interesting structural system for applications in projects, providing layout changes because they don't require the use of beams. Analyses of this type of slab are complex and are often designed using software developed for linear analysis based on the classic plate theory, using numerical analyses (SKORPEN ET AL [1]). The Finite Element Method (FEM) and Grid Analogy Method are examples for numerical analyses, both procedures widely used by technical designers.
The use of numerical models that simulate the slabs-columns connections as being pinned support (singularities) provide results with high concentration of strains across these areas, resulting in peak of bending moments in the slab and distortions of the values of bending moments columns. Results of this type require a more refined analysis to be used in structural designs. According $\mathrm{CHOI}$ ET AL [2], the structural behavior of the slab- columns connections is very complicated, since they are composed of two different types of elements: beams (columns) and plates (slabs).

It is known that the slabs-columns connections are not punctual;

\section{Figure 1 - Distribution of bending moments on a flat slab adapted of SKORPEN ET AL (1)}

\section{Code}

TMH 7 1989, Code of practice for the Design of

Highway Bridges and

Culverts in South Africa, Part 3 (discussed under footings)

\section{Column strip} width

$b_{\text {col }}+3 d$ (if the width of the footing is greater than $1,5\left(b_{\text {col }}+3 d\right)$ $33,33 \%$ Edge strip
SANS 10100 2000, The structural use of concrete, Part 1
$\left[\frac{2}{D / B+1}\right] x 100$ $\left[\frac{D / B-1}{D / B+1}\right] x 100$

Eurocode 2, Design of concrete structures EN 1992-1-1:2003 (E)

BS 81 10:1997 Structural use of concrete, Part 1 $b_{\text {col }}+3 d$ (if the width of the footing is greater than $1,5\left(b_{\text {col }}+3 d\right)$
$66,67 \%$

$33,33 \%$

$b_{\text {col }}+3 d$ (if the width of the footing is greater than $1,5\left(b_{\mathrm{col}}+3 d\right)$
$66,67 \%$

$\mathrm{b}_{\text {col }}=$ column dimension in the long direction; $\mathrm{d}=$ depth of the slab; $\mathrm{D}=$ longer plan dimension of footing; $\mathrm{B}=$ shorter plan dimension of footing

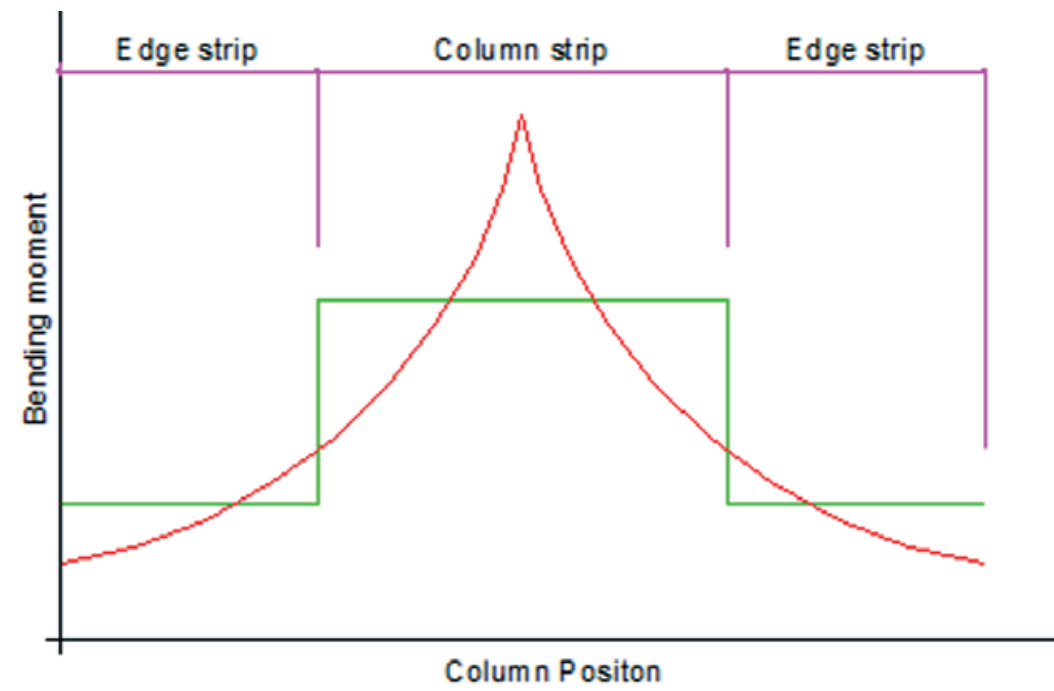


they are regions of complex behavior. The numerical models using the columns as pinned supports despise the favorable effect of that interaction region. This effect should be taken into account to provide a better analysis of the slabs-columns connections. Therefore, it is necessary improve the models to obtain suitable efforts across these areas.

There are several possible models that take these effects into account, which can vary in complexity, and many of them are not suitable for current use in structural projects. MURRAY ET AL [3] comments that the way to model slabs-columns connections behavior is the critical point of analysis of flat slabs.

The purpose of this paper is to contribute to the development of models for structural analysis that can be used in projects of reinforced concrete structures, integrating flat slabs with the columns, using the Finite Element Elastic Linear Analysis. To ease the analysis of the slabs-columns connections and to obtain results for the design of the slabs, this work also tried to contribute in graphic displays of results using available resources in other areas of engineering, allowing 3D views and mapping sections in regions of interest.

The softwares SAP2000 [4], ArcGIS / ArcMap [5] and Global Mapper [6] have been adopted as tools for the development of this work.

\section{Modeling alternatives slabs-columns connections}

Theoretically, when a concentrated load is applied on a slab, it causes a bending moment that tends to infinity in its point of application, creating singularity points. Consequently, in a numerical method, when a column for supporting slabs is modeled as a pinned support, it causes the effect of a concentrated load in the opposite direction, resulting in very high bending moments on the load application point and around it. Studies by PUEL [7] showed that those moments will be greater as the mesh gets more refined. According SKORPEN ET AL [1], the basics of using linear FEM to analyze flat slabs is commonly understood by most designers. However, the modeling of connections between column and slab is still open to numerous forms of designer interpretation.

The NBR 6118: 2014 [8] and even the Eurocode 2 [9], which is a respected code in the technical community, do not prescribe a type of analysis or modeling nor indicate how to interpret the results obtained from a numerical analysis of concentrated loads effect. This naturally leads to many forms of interpretation that depend on how the slabs-columns connections are modeled, leaving it to the experience and feeling of the designers.

Another approach for the design of flat slabs is use the Equivalent Frames Method, which takes into account the plastic behavior of the cross sections of reinforced concrete slab, that leads to a design with redistribution of bending moments. According MURRAY ET AL [3], the design of flat slabs is governed by national codes of practice that have developed as a result of empirical research. Some international codes prescribe criteria to distribute the peak bending moments for the footings design, as shown in Figure 1.

The NBR 6118: 2014 [8], item 14.7.8, allows the structural analysis of flat slabs by the Equivalent Frames Method (EFM). This is a process based on an approximate elastic analysis, with redistribution, taking in each direction multiple frames to obtain the internal forces, whose inertias will be equal to the slab's limited by the half of the distance between two rows of columns, as shown in Figure 2.

For each frame the total loading must be considered. The distribution of moments obtained in each direction, according to NBR 6118: 2014 [8], item 14.7.8, is as follows:

- $45,0 \%$ of positive moments for the two inner strip;

- $27,5 \%$ of positive moments for each of the external strip;

- $25,0 \%$ of negative moments for the two inner strip;

- $37,5 \%$ of negative moments for each of the external strip.

The Equivalent Frames Method provides more economic results compared with projects based on linear elastic analysis, but should be used only in the Ultimate Limits State (ULS) checks.

\section{Figure 2 - Strip distribution of bending moments according NBR $6118: 2014$ (8)}
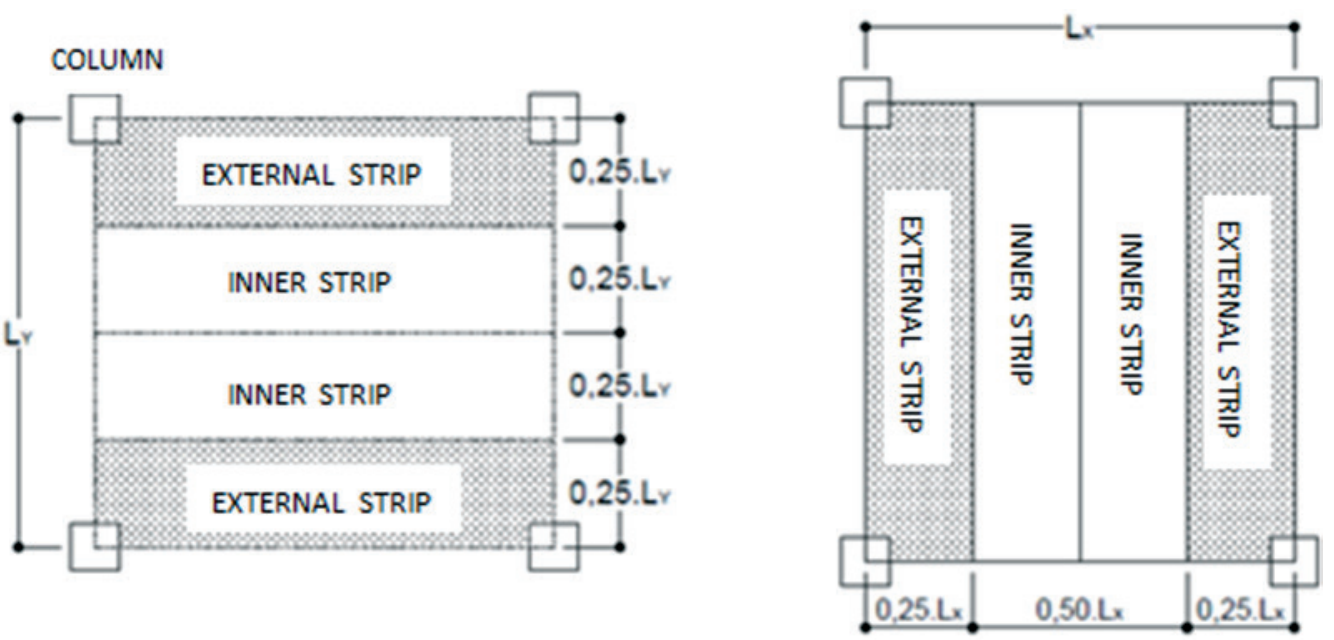


\section{Figure 3 - Idealizations of column/flat slab connections (ROMBACH (10))}
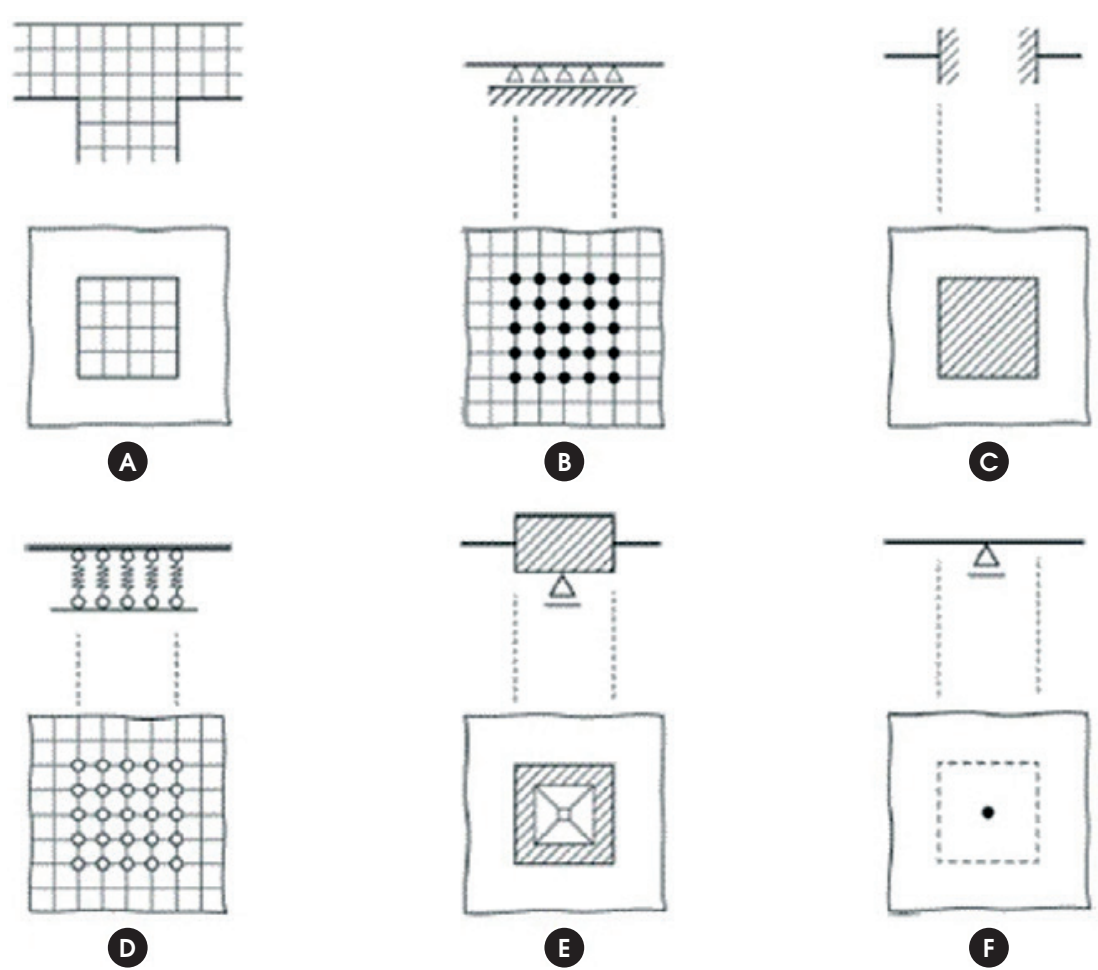

c

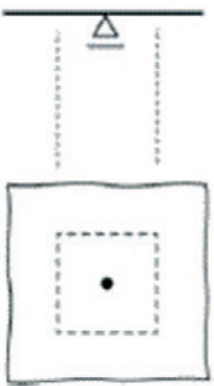

F

For checks of Serviceability Limits Service (SLS), an Elastic Analysis Linear or Nonlinear analysis is still required. However, the Equivalent Frames Method cannot be used in flat slabs with considerable asymmetries, mainly when they occur in the positioning of the columns.

ROMBACH [10] summarized some ways to model the slabs-columns connections, shown in Figure 3.

a) Full $3 \mathrm{D}$ continuum model - this model is accurate, but very time consuming;

b) Pinned supports over all nodes above the column - does not represent accurately the rigidity of the pillar;

c) Encased supports assigned to the edge of the column in the shell model - does not represent accurately the rigidity of the pillar;

d) Spring supports assigned to the column area in the shell model - no restrictions;

e) Rigid column head - this represents accurately the rigidity of the pillar;

f) Point support at one node - this is the least accurate way of modeling a support, but probably the most used.

SKORPEN ET AL [1] presented a comparative between the traditional methods of analysis of flat slabs (summarized in Figure 1) with the finite element method and also with experimental results. Figure 4 shows this comparative of bending moments on the slabscolumns connections, comparing the methods presented in Figure 1 (SD method) with the analysis by FEM, considering the slabscolumns connections idealized by ROMBACH [10].
The cases (a) and ( $\mathrm{g}$ ) showed the best results of this comparative. According to the authors, the case (i) should be avoided as it does not take into account the columns rigidity. The comparative with the experimental tests confirm the results presented for the cases (a) and $(\mathrm{g})$ and also to the criteria presented in Figure 1.

HENNRICHS [12] studied, from a reference slab with dimensions of $10 \times 10 \mathrm{~m}$ and a middle column, displacements, positive and negative bending moments, and reaction in the middle column, using the linear analysis based on the classic plate theory. When considering the middle column as pinned support or as load distributed in the cross-section area column, there was little difference in the positive moments, displacements and reaction in the middle column. The maximum negative moment, however, decreases, and the diagram of moments became smoother in the region of the middle column. These results were compared with numerical methods, including Finite Element Method and Grid Analogy Method. The values were similar for fine meshes, with significant differences for coarse meshes. HENNRICHS [12] also analyzed a model by the MEF considering the middle column with Solid elements, trying to simulate the real dimensions of the element (Figure 5).

The results in terms of positive bending moment, load on the column and maximum displacements showed very similar to the results obtained by the theory of elastic plates. However, considering the negative moments in the middle column, there were peak values in the column's edges. These peaks were higher on columns with one dimension very smaller than other (elongated columns). PEDROSO [13] studied criteria of prestressed flat slabs project, 
Figure 4 - Comparative of bending moment over the column (SKORPEN ET AL (1))
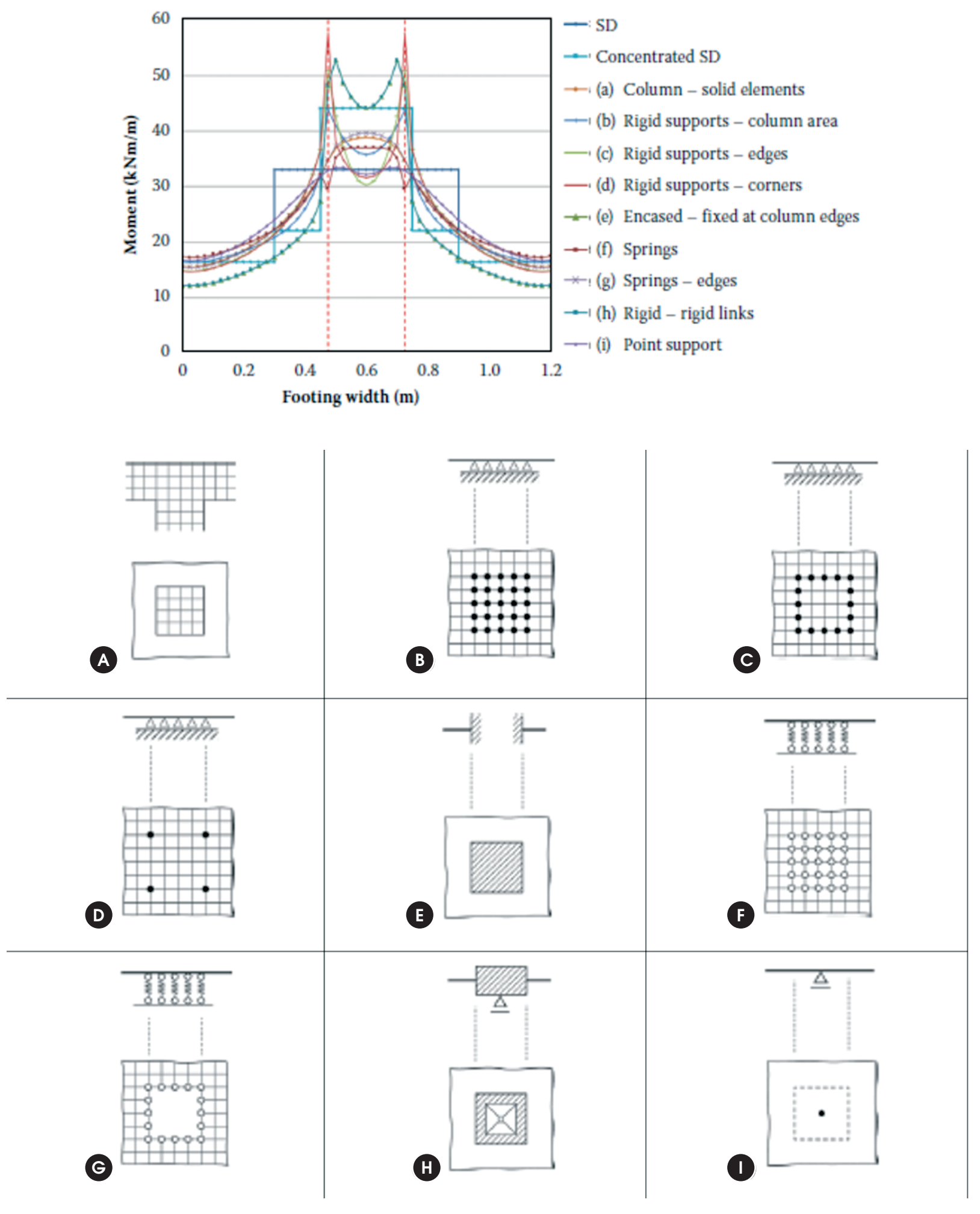
Figure 5 - Column modeled as solid element (HENNRICHS (12))

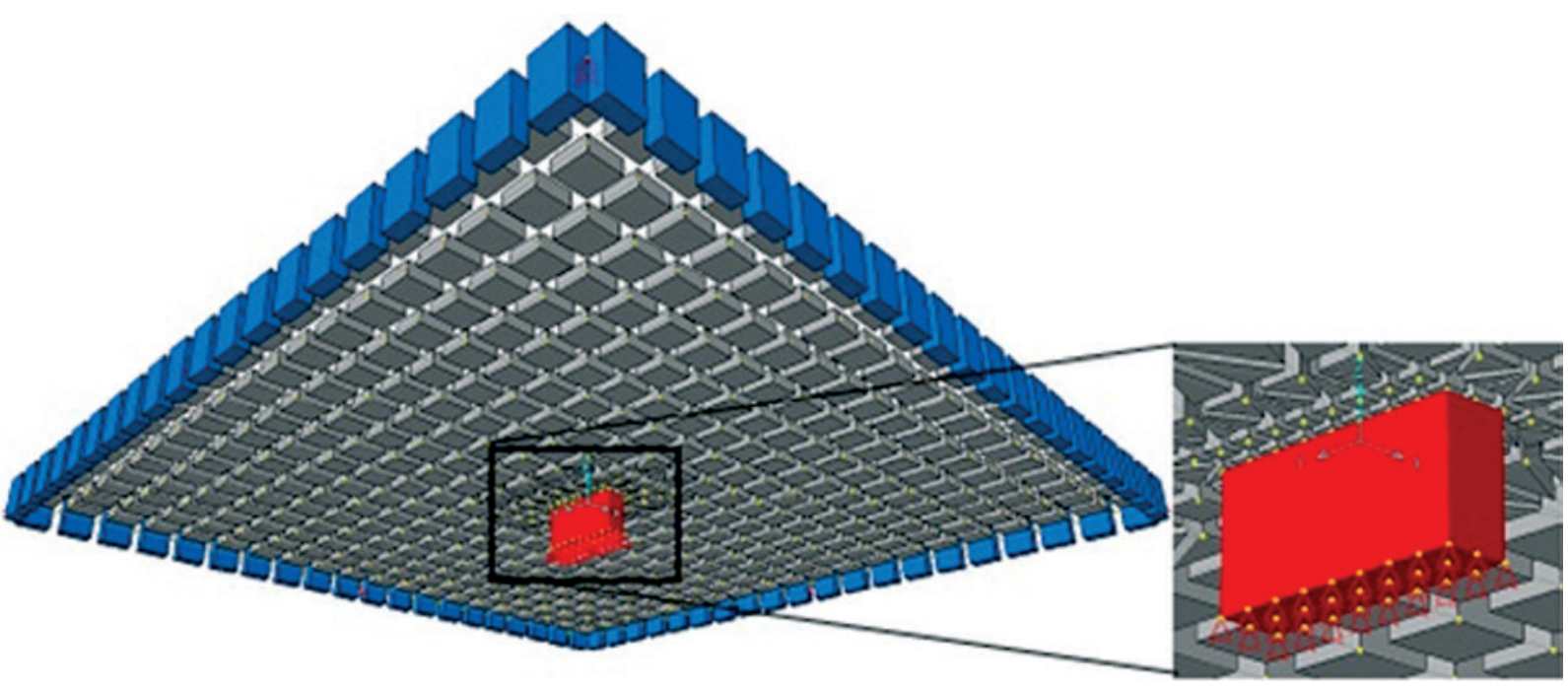

Figure 6 - Bending moments - Section C - Models 01/02/03/04 (PEDROZO (13))
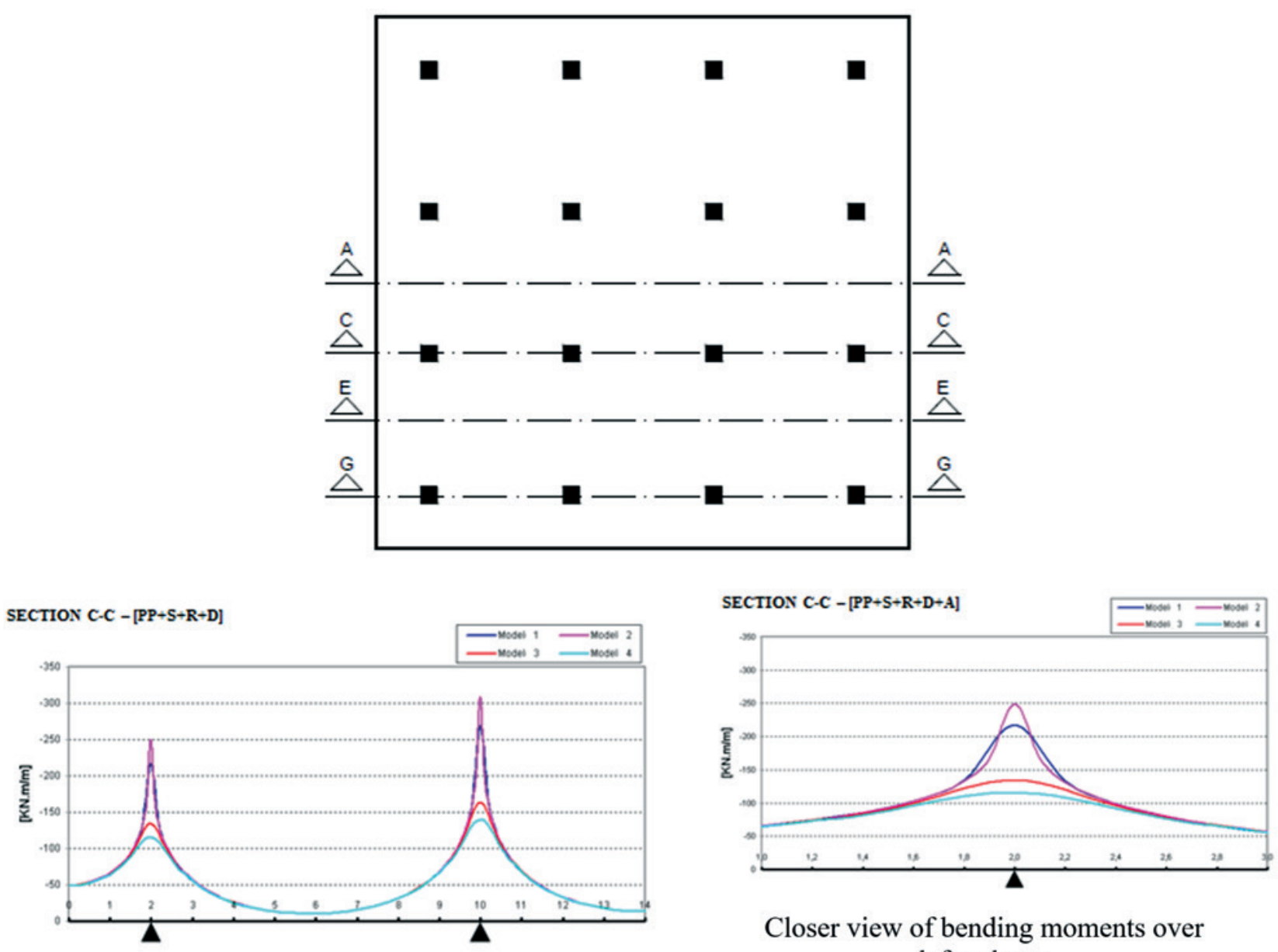

Closer view of bending moments over left column 
Figure 7 - Comparative FEM/EFM - Section E (PEDROZO (13))
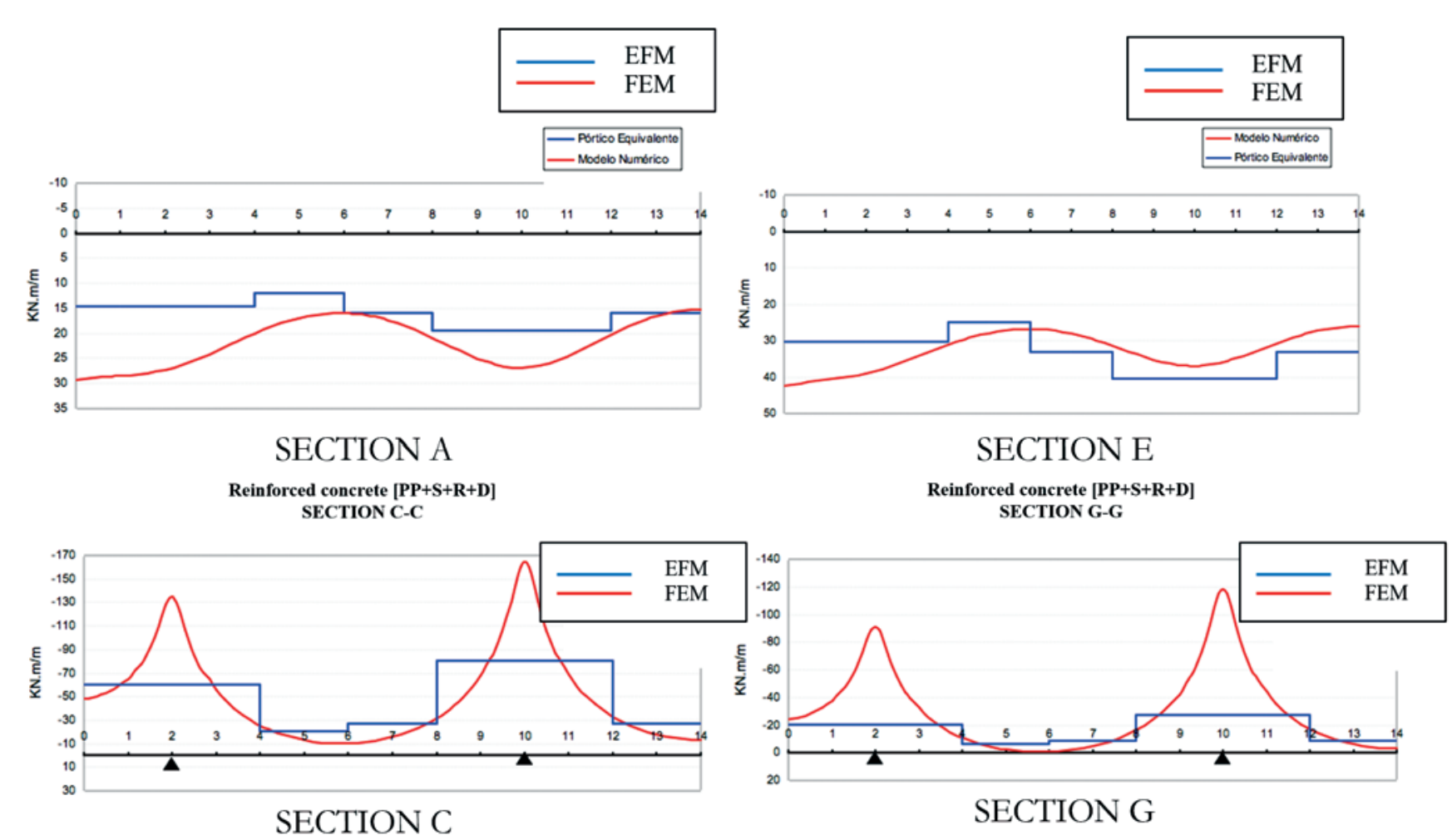

developing design examples with and without cantilevers, comparing the results with the Equivalent Frames Method and the FEM, using the software SAP 2000 [4]. In the analysis by the FEM, examples were studied modeling column as a pinned support and the reaction distributed in the slab in the cross-section area column, with the opposite direction to the application of load on the slab.

The models 01 and 02, presented in PEDROSO [13], consider the column as pinned support, with a mesh of $20 \times 20 \mathrm{~m}$ and $10 \times 10 \mathrm{~m}$ respectively. The models 03 and 04 distribute the column reaction on the slab, but the model 04 considers the cross-section area column projected at the geometric center of the slab. As a result of these models, the bending moments gets a smoothed surface, more evident in the model 04 (Figure 6).

There was also a comparison of bending moments obtained in the slab for the Model 04 (which considers the analysis by FEM) with the the Equivalent Frames Method (EFM). This type of comparison can provide criteria for design the slab in ULS, based on linear elastic analysis (Figure 7).

The results of this comparison showed that the positive moments had a significant difference on the external columns. The same happened with the negative moments, being numerically greater the moments obtained by the FEM.

PUEL [7] studied on symmetric and asymmetric flat slabs the behavior of the bending moments in slab and columns by modeling the columns as pinned support, as reaction distributed the slab in the cross-section area column and also reaction distributed in the column region projected at the geometric center of the slab (similar criteria to the effects of a wheel on a deck of a bridge), as shown in Figure 8.

PUEL [7] also studied the existence of a rigid sector at the crosssection column head, as prescribed by NBR 6118: 2014 [1], item 14.6.2.1: "The span of linear elements belonging to the common area at the crossing of two or more elements may be considered rigid (nodes of finite dimensions) ". (Figure 9).

The main idea of the model proposed in this paper is to distribute the column reaction in a given area, with a load applied in the bottom-up direction on the slab, simulating the column dimensions and its interaction with the slab. This procedure is similar to the one used to smooth the negative moments over the supports in continuous beams of reinforced concrete, recommended by the NBR 6118: 2014 [8] and also showed by GLÓRIA [11]. This model, as will be demonstrated later, eliminates the singularity, gets the negative bending moments diagram smoothed in both directions, and makes the model less dependent of the mesh adopted for the analysis. And, besides providing good results for the design, it is a much simpler model than the others found in the bibliography.

\section{Methodology for column reaction distribution on the slab}

When the column is positioned asymmetrically in relation to the slab, the load is asymmetric or horizontal forces exist, besides the 
normal force, bending moments appear in the column. The application of the load as a reaction distributed in the slab at the column region should take into account binary forces, calculated from the sum of the bending moment applied to the slab, from the upper and lower span column.

The effect of connection between column $x$ slab is obtained through a model analogous to the one used in continuous beam, which is modeled half of the column above and half of the column below. With this, when there is an asymmetry in the loading and/or the geometry between the slab and punched column, spin happens on the joint at the column $x$ slab connection, which causes bending in the column, as shown in Figure 10.

The methodology for simulating the axial forces and bending on the column as a reaction applied to the slab consists an iterative process, shown briefly in Figure 11.
The necessary steps in this process are presented in detail as follows:

1) Initially, analyze the structure modeling the column as pinned support to obtain the diagrams of normal forces and bending moments on the column;

2) Find the value of " $q$ " and " $q_{M}$ ". Overlap the normal (q) and bending $\left(q_{M}\right)$ column effects, getting a final loading diagram with $q_{E}$ and $\mathrm{q}_{\mathrm{D}}$ values, adding it in the slab.

Where:

$q=$ Load value applied as a reaction on the slab due to the column normal stress;

$\mathrm{a}=$ colum dimension at the moment action plan;

$\mathrm{b}=$ another column dimension;

$\mathrm{P}=$ axial force on the column;

$\mathrm{M}_{\text {laje }}=$ slab bending moment, obtained by the sum of upper

\section{Figure 8 - Alternatives to represent the column as support for flat slab (PUEL (7))}

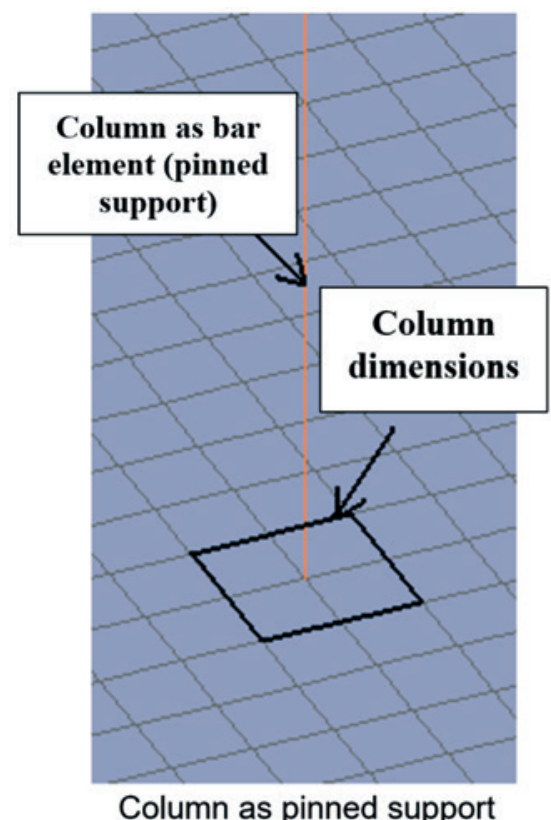

Column as pinned support

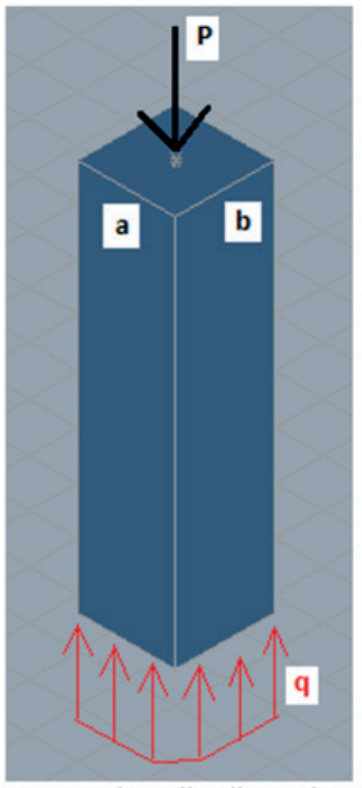

Column as reaction distributed to the slab

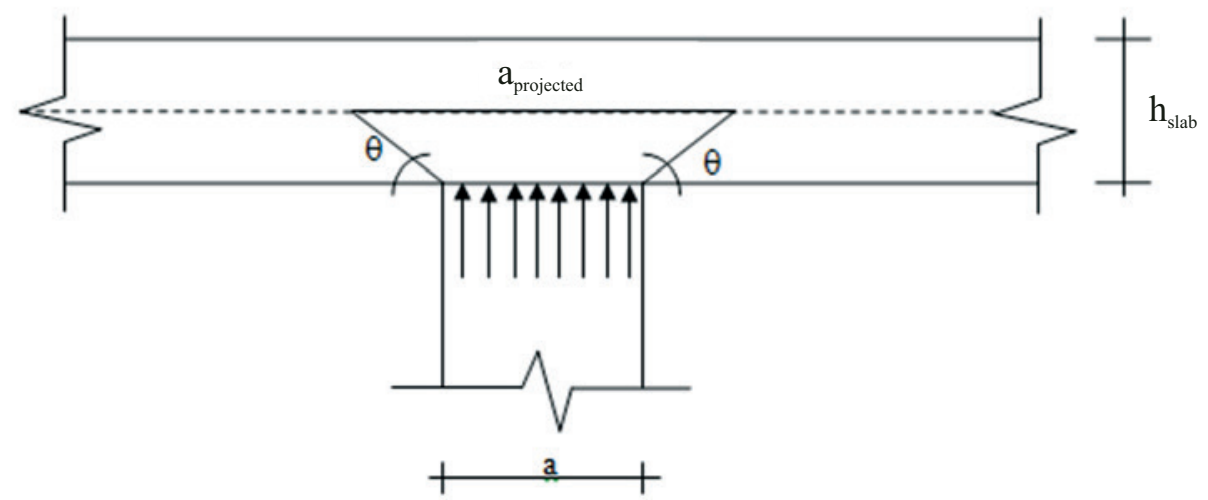


$q=\frac{P}{a \cdot b} \quad \pm \quad q_{M}=\frac{6 \cdot M_{\text {laje }}}{a^{2} \cdot b} \quad=\quad q_{E}, q_{D}$

q

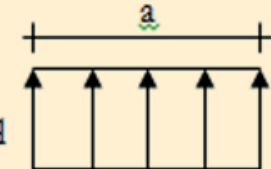

$\pm$

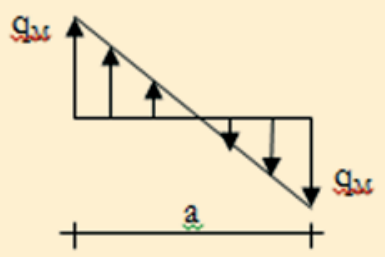

$=$

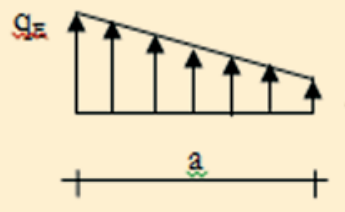

moment column and lower moment column;

$\mathrm{q}_{\mathrm{M}}=$ Edge value load applied as reaction on the slab;

$\mathrm{q}_{E}=$ load at the column left face;

$\mathrm{q}_{\mathrm{D}}=$ load at the column right face.

3) Replace column modeled as line (half up and half down) for a hinged support, as shown in Figure 12.

4) Analyze the structure again, obtaining the forces on column joint restricted (red circle in Figure 12);

5) The support reaction should be zero or close to zero. If not, correct the initial axial force from the difference found in this iteration;

6) Through spin joint, check the new active moment, multiplying the spin joint by the spring with stiffness that simulates the rigidity of the column line, modeled half upper and half lower of the slab, as shown in Figure 13.

The spring stiffness $\left(k_{\text {mola }}\right)$ is calculated as follows.

$$
\begin{aligned}
& k_{\text {mola }}=k_{\text {sup }}+k_{\text {inf }} \\
& k_{\text {mola }}=\frac{3 \cdot E_{c s} \cdot I_{\text {sup }}}{L_{\text {sup }} / 2}+\frac{3 \cdot E_{c s} \cdot I_{\text {inf }}}{L_{\text {inf }} / 2}
\end{aligned}
$$

Where: $\mathrm{k}_{\text {mola }}=$ spring stiffness, which corresponds to the sum of the stiffnesses of upper and lower span column;

$\mathrm{E}_{\mathrm{cs}}=$ Secant Elastic Modulus of concrete;

$\mathrm{I}_{\text {sup }}=$ upper column inertia;

$\mathrm{I}_{\text {inf }}=$ lower column inertia;

$\mathrm{L}_{\text {sup }}=$ upper column dimension;

$\mathrm{L}_{\text {inf }}=$ lower column dimension.

Finally, the moment is calculated as follows:

$$
M_{\text {laje }}=k_{\text {mola }} \cdot \varphi
$$

\section{Where:}

$\mathrm{M}_{\text {laje }}=$ Slab action moment;

$\mathrm{k}_{\text {mola }}=$ springs stiffness;

$\phi=$ column joint spin restricted (red circle in Figure 12), obtained by load diagram with $q_{E}$ and $q_{D}$, applied as a reaction on the slab, as shown in Figure 14.

If the bending moment in this iteration that occurs the column joint restricted is not equal to the previous bending moment, used to find $q_{E}$ and $q_{D}$, it is necessary to repeat the process. Convergence occurs when the moment obtained in the current iteration is equal or practically equal to that used in the previous interaction. It is necessary to stipulate a minimum limit of convergence for the spring moments.

Figure 9 - Rigid sections according NBR 6118:2014 (8)

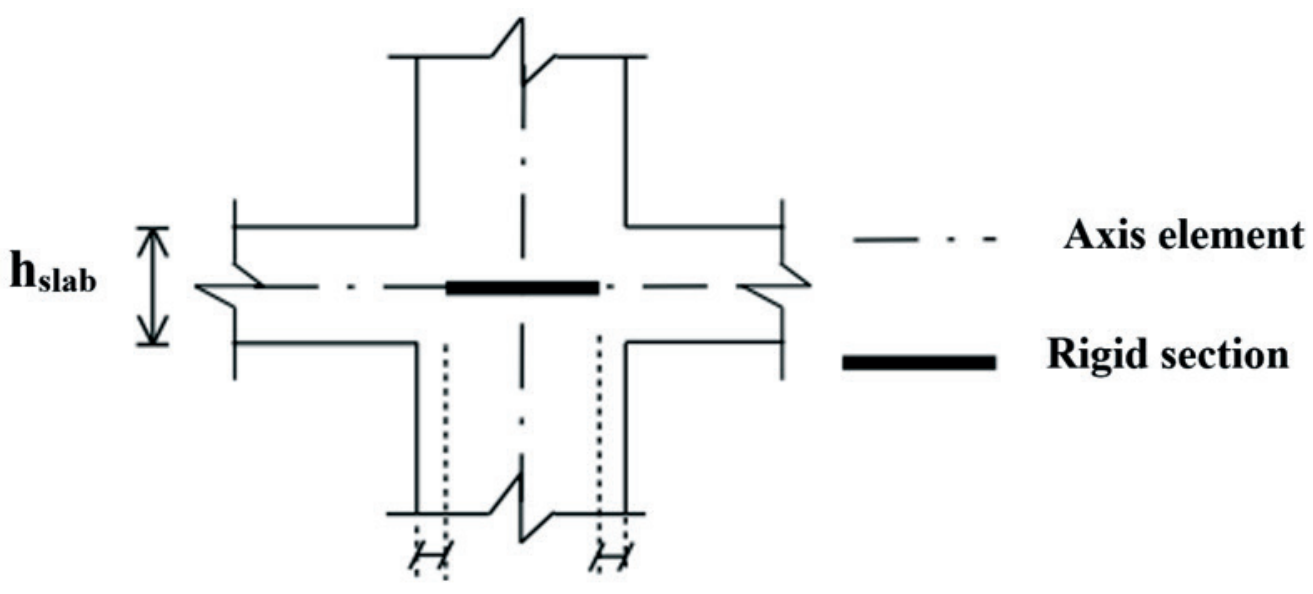

$0,3 \mathrm{~h}_{\text {slab }} \quad 0,3 \mathrm{~h}_{\text {slab }}$ 
Figure 10 - Column modeled as continuous beam model (PUEL (7))

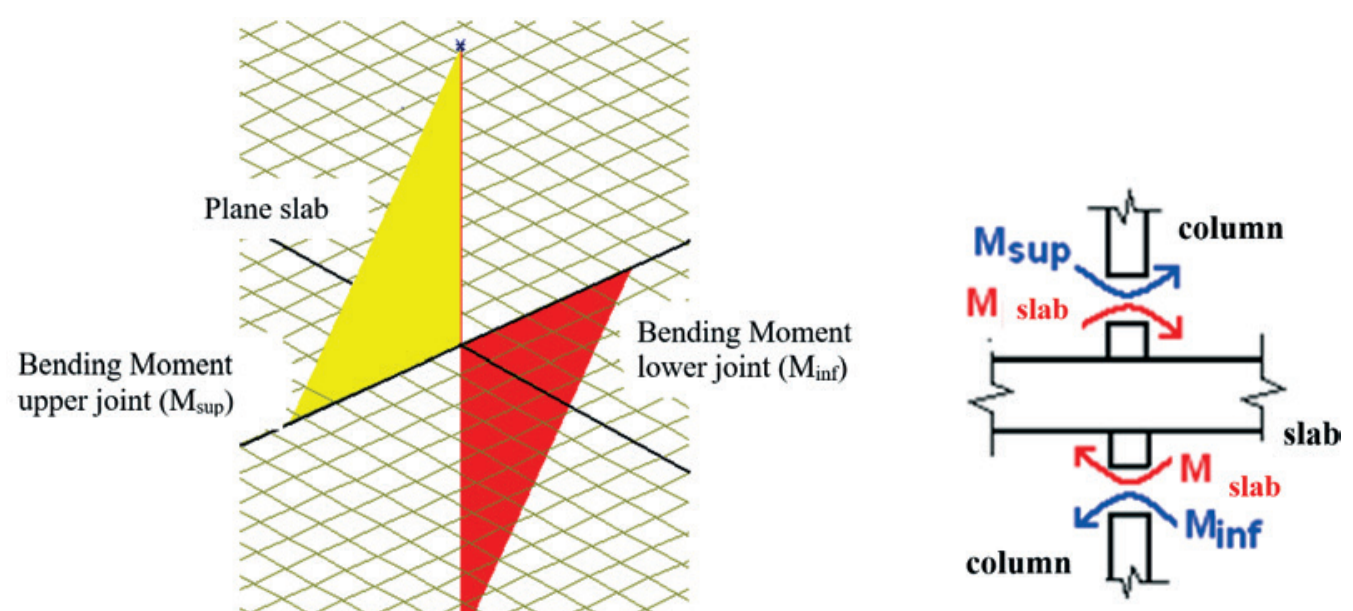

Figure 11 - Method scheme simulating the column as reaction to the slab (PUEL (7))

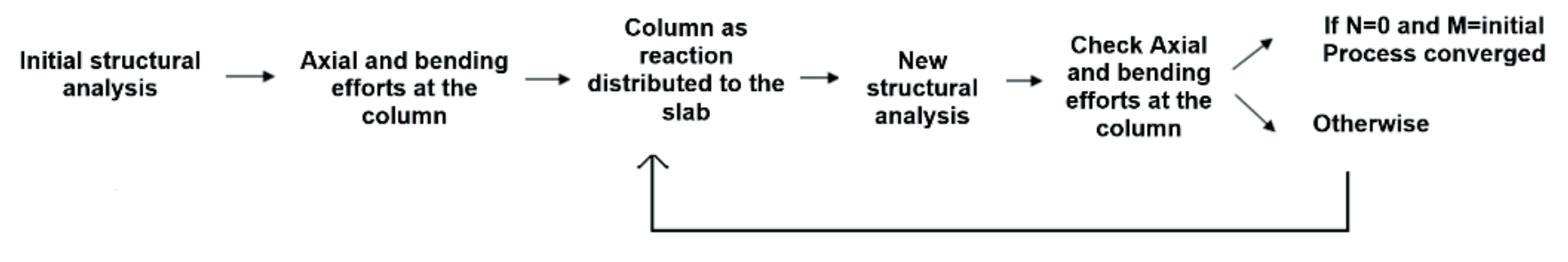

Figure 12 - Column modeled as beam replace for a hinged support (PUEL (7))

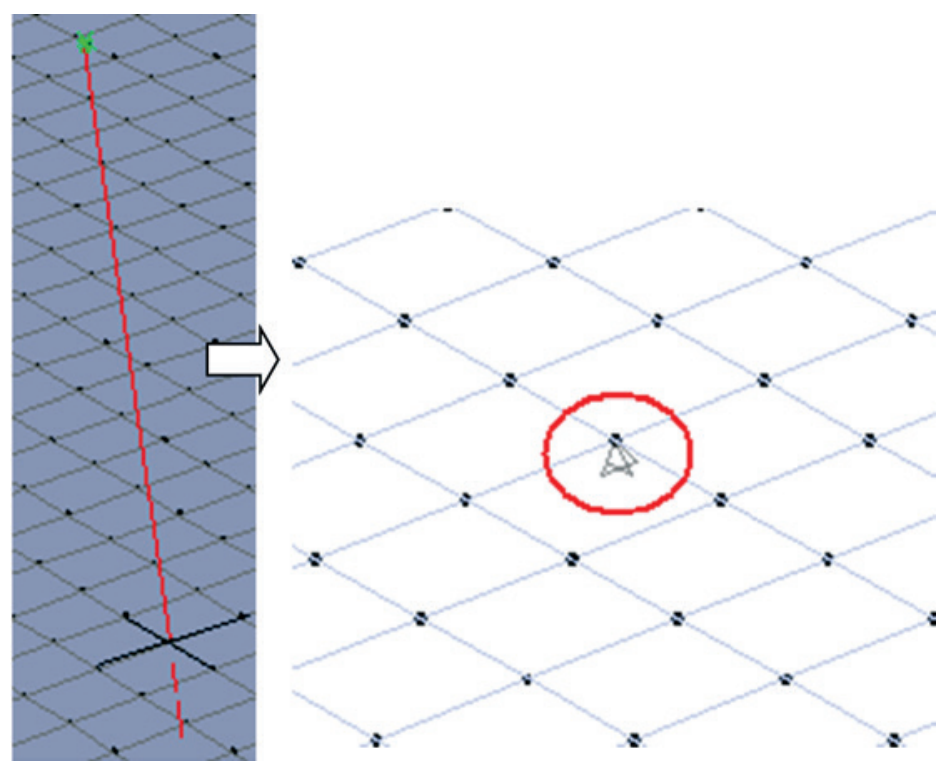


Figure 13 - Spring stiffness: half column upper and half column down (PUEL (7))

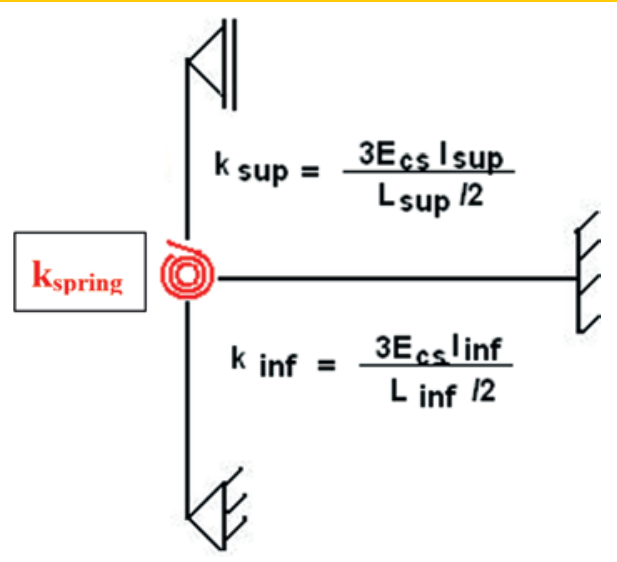

7) Thus, when the process does not converge, it is necessary to adjust the " $q$ " and " $q_{M}$ " values from the new axial forces and bending moment values, composing a new load diagram from $q_{E}$ and $q_{D}$ values. This new diagram will once again applied to the slab until it has the convergence of axial force and bending moment, within a minimum tolerance adopted by the designer.

\section{Column as reaction on the slab}

To represent the pillar as a reaction on the flat slab distributed at the column cross-section area, it is necessary that the geometry of the mesh used in FEM modeling matches these dimensions. The same occurs when there is a rigid sector on the column head and when it distributes the reaction in the column region projected at the geometric center of the slab (similar criteria to the effects of a wheel on bridge slabs)

Thus, it is necessary to create transitions in the mesh to make this geometric adjustment, as shown in Figure 15 and Figure 16.

The adoption of rigid sectors on head column follows the NBR 6118: 2014 [8] requirements, item 14.6.2.1. This model was also suggested by ROMBACH [10] Case "e" Figure 3.

\section{Models description}

The numerical analyses made in this paper model the column in different ways, the first being a bar connected directly on the slab plate elements. This modeling is used only for comparison with the results obtained in more suitable models. Models were made to replace the column reaction as load applied to the slab in opposite direction as gravity loads, using the column cross-section area and column cross-section area projected at the geometric center of the slab. Finally, models were made with rigid sectors to simulate the column head, with or without distributed reactions.

Two structures were studied, one with a symmetrically middle column and another with an asymmetry on the column position. The models developing for each structure were called "Cases" and are presented in the next chapter.

The Figure 17 shows the structure with an asymmetric column position, with a $1 \mathrm{~m}$ eccentricity to the vertical axis when compared with the symmetrical structure.

With:

- $\mathrm{F}_{\mathrm{ck}}=25 \mathrm{MPa}$;

- $E_{\mathrm{cs}}=2,38 \times 107 \mathrm{kN} / \mathrm{m}^{2}$;

Overload $=2,0 \mathrm{kN} / \mathrm{m}^{2}$;

\section{Figure 14 - Column joint spin restricted (PUEL (7))}


Figure 15 - Rigid sector on the column head

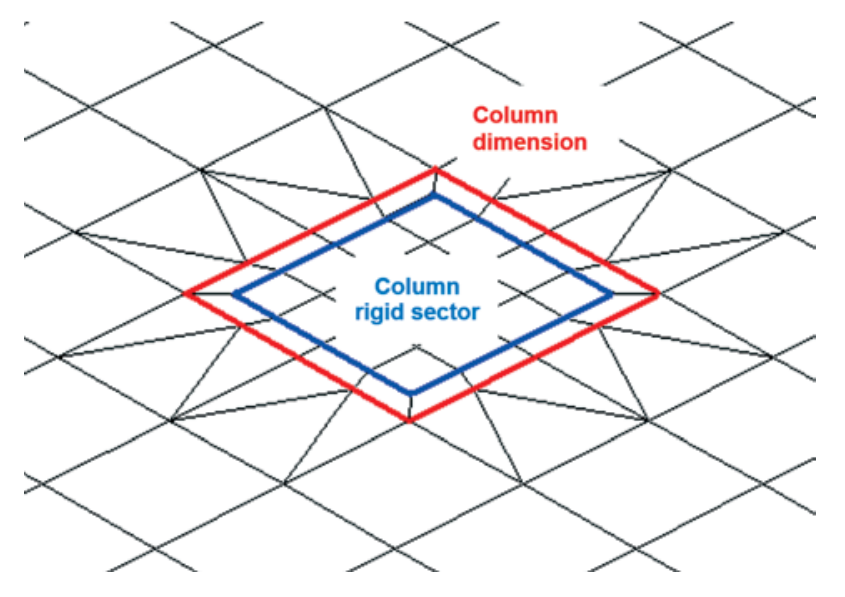

Floor covering $=1,0 \mathrm{kN} / \mathrm{m}^{2}$;

Self wheigth $=0,16 \times 25=4,0 \mathrm{kN} / \mathrm{m}^{2}$;

Slab thickness $=16,0 \mathrm{~cm}$

Total load applied to the slab $=7,0 \mathrm{kN} / \mathrm{m}^{2}$;

Vincinity beams sections $20 \times 50 \mathrm{~cm}$;

Vincinity columns sections $20 \times 20 \mathrm{~cm}$;

Middle column sections $50 \times 50 \mathrm{~cm}$;

$\mathrm{k}_{\text {spring }}=371875 \mathrm{kNm}$;

Rigid sector dimension $=40,4 \mathrm{~cm}$;

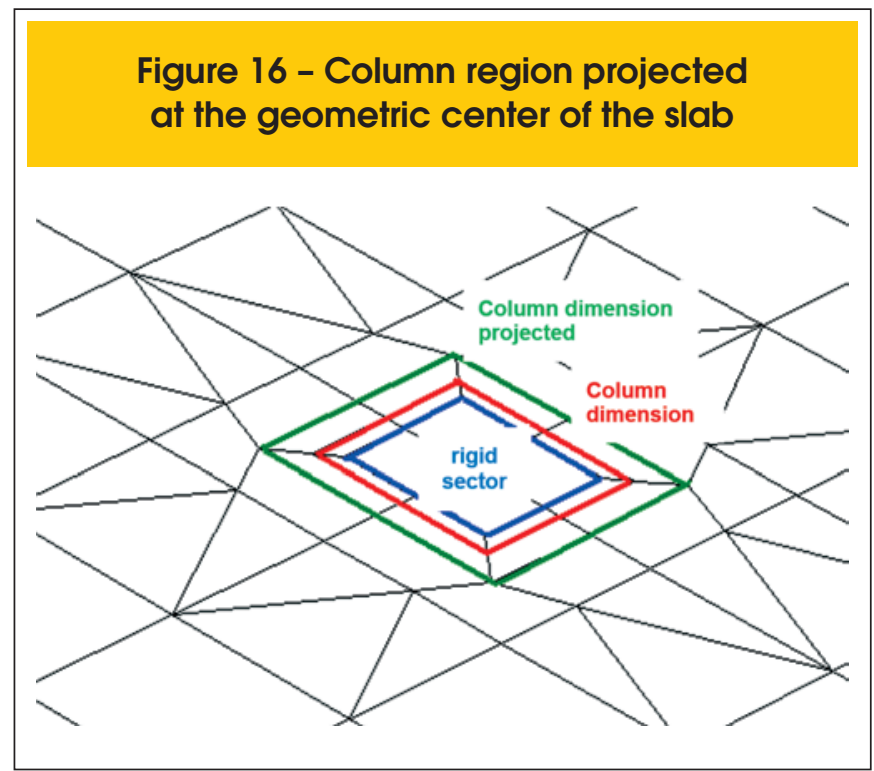

Column projected dimension $=66 \mathrm{~cm}$;

- Rigid sector stiffiness $=100 x$ slab thickness stiffness.

As boundary conditions, the upper and lower column joints were restricted with roller and hinged supports, respectively. This model is analogous to the continuous beam prescribed in

NBR 6118: 2014 [8].

The slab was modeled with "THIN PLATE" elements, according to the Thin Plates Theory, based on the of Kirchhoff's theory (DKQ discrete Kirchhoff quadrilateral), which ignores transverse shear

\section{Figure 17 - Description of adopted model (PUEL (7))}

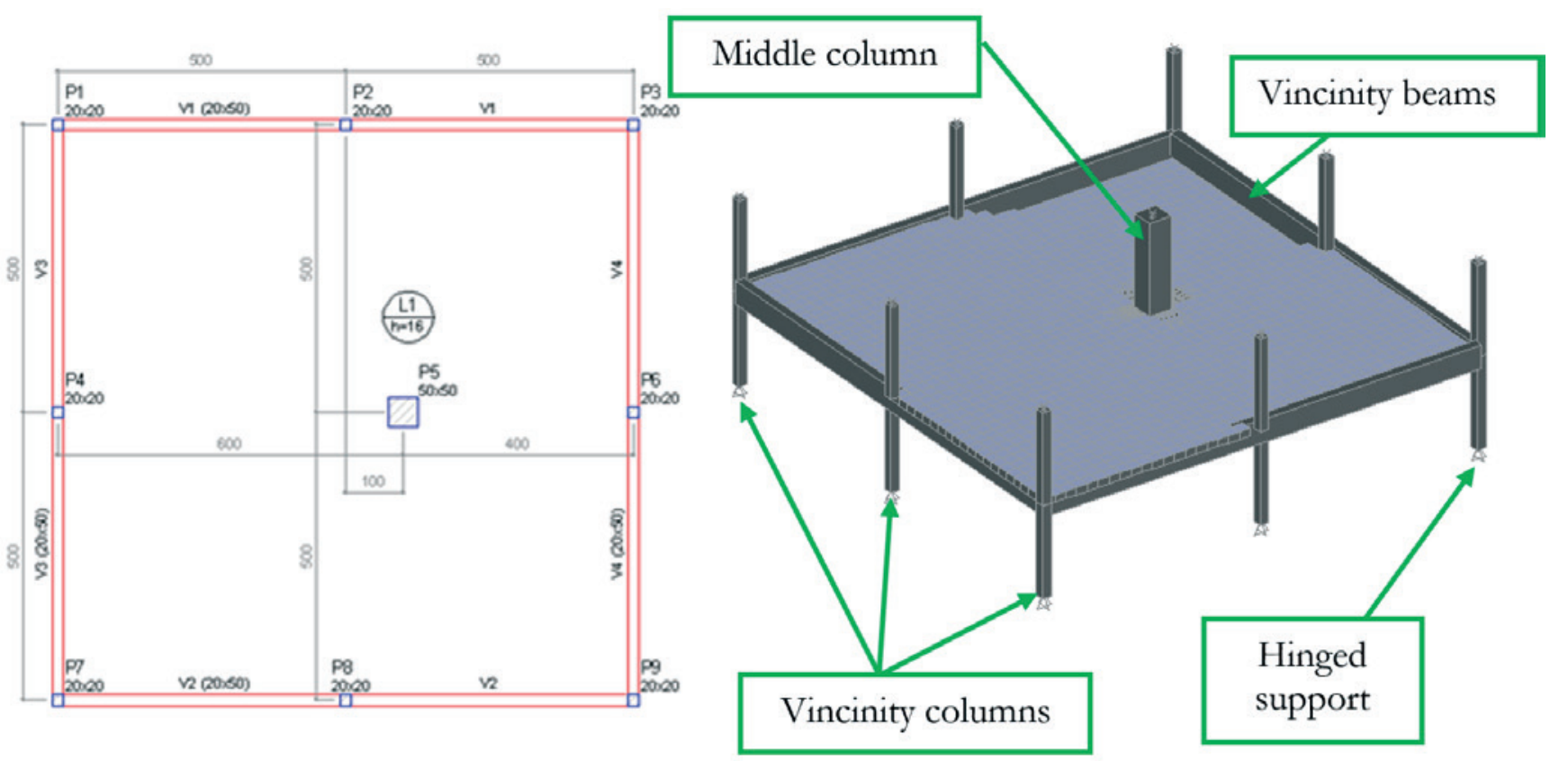




\section{Table 1 - Summary of used models}

\begin{tabular}{|c|c|c|c|}
\hline Case & $\begin{array}{l}\text { Asymmetry middle } \\
\text { column }\end{array}$ & $\begin{array}{l}\text { Rigid sector } \\
\text { middle column }\end{array}$ & Subcases \\
\hline 1 & No & No & $\begin{array}{c}1.1 \text { - Column as pinned support } \\
1.2 \text { - Column as reaction distributed to the slab } \\
\text { 1.3- Column as reaction distributed projected at the } \\
\text { geometric center of the slab }\end{array}$ \\
\hline 2 & No & Yes & $\begin{array}{c}2.1 \text { - Column as pinned support } \\
2.2 \text { - Column as reaction distributed to the slab } \\
2.3 \text { - Column as reaction distributed projected at the } \\
\text { geometric center of the slab }\end{array}$ \\
\hline 3 & $1 \mathrm{~m}$ & No & $\begin{array}{c}3.1 \text { - Column as pinned support } \\
\text { 3.2- Column as reaction distributed to the slab } \\
\text { 3.3- Column as reaction distributed projected at the } \\
\text { geometric center of the slab }\end{array}$ \\
\hline 4 & $1 \mathrm{~m}$ & Yes & $\begin{array}{c}4.1 \text { - Column as pinned support } \\
4.2 \text { - Column as reaction distributed to the slab } \\
4.3 \text { - Column as reaction distributed projected at the } \\
\text { geometric center of the slab }\end{array}$ \\
\hline
\end{tabular}

effects. The columns and beams were modeled with "FRAMES" elements.

\section{Summary models analyzed in the software SAP 2000 [4]}

The models that will be studied in this paper are summarized in Table 1.

Remark: The Cases presented were modeled with different meshes, whose dimensions are cited in the results.

\section{Analysis results}

Models of symmetrical flat slabs (Case 1.1) are shown in Figure 18. The results (Figure 19) showed that the slabs positive moments are little influenced modeling the column as line or by the mesh adopted. However, the same cannot be said about the negative moments in the slab.

The Figure 19 also shows that the maximum negative moment over the column P5 is strongly influenced by the mesh adopted, which tends to always increase with the refinement of this mesh. This moment is not suitable for use in structural analysis, showing that the column modeled as a bar directly connected to the slab should be avoided if the purpose analysis is to obtain bending moments in the region slab $x$ column connection

It is shown in Figure 20 the bending moments over the column P5, section 1-1, using mesh 12.5, shown in Figure 18.

The bending moments diagrams provided by the Cases 1.2 and 1.3 were smoothed over the column P5 compared with Case 1.1 (where is pinned considered) because they consider the column reaction distributed in the slab. Analogous results were obtained by PEDROZO [13]. The other meshes studied also showed similar results as presented in Figure 20, showing that the Cases 1.2 and 1.3 are less sensitive to mesh used. Therefore, modeling the column reaction as a distributed load solves the singularities, providing suitable moments for structural analysis. The distribution of these loads over the cross-section area column or the crosssection area column projected in the geometric center of the slab changes a little the value of the maximum moment. The Figure 21, which shows the maximum moments over the column P5 for Cases 1.1, 1.2 and 1.3 for the various meshes studies, confirms these partial conclusions.

Besides, it can be noted that Case 1.1 clearly shows the singularity problem, because the negative moments over the column increase when finer meshes are used.

The use of a rigid section at the column head also provides a suitable modeling. The use of distributed loads together with the rigid sections smooth the moment diagram over the column, but there is some perturbation of moments within de column. The moments obtained on the column face have very similar values to each other. It can be an appropriate alternative to represent the moments on this region.

The Figure 22 shows the bending moment's variation at the P5 column face to the Cases 2.1, 2.2 and 2.3.

It may be noted that the values are practically the same for Cases 1.2 and 1.3, obtained at the P5 column face, whatever mesh used. In the Case 2.1, the moments at the face using a mesh with $12,5 \times 12,5 \mathrm{~cm}$ were almost the same obtained on Cases 1.2, 1.3, 2.2 and 2.3. The rigid section at column head allows modelling adequately the column stiffness, also observed by ROMBACH [10] (Case "e" Figure 3).

When introduced an asymmetry in the column position, the structural behavior changes significantly. To calculate the distributed reaction must include the column bending moment.

It's showed at Figure 23 the bending moment on the flat slab with asymmetry in the column position. It was used a mesh with $25 \times 25 \mathrm{~cm}$, carrying out refinements in the cross-section area column, using meshes with $12,5 \times 12,5 \mathrm{~cm} \quad 6,25 \times 6,25 \mathrm{~cm}$ and $3,125 \times 3,125 \mathrm{~cm}$. 
The results are shown in graphs, using the Section 1 as reference. The Figure 24 shows the bending moments for the Cases 3.1 / 3.2 / 3.3. The Figure 25 shows the maximum negative bending moments over the P5 column for the Cases 3.1 / 3.2 / 3.3.

It is clearly noted that modeling column as bar directly connected to the plates elements is not an appropriate model. Modeling column reaction distributed at the cross-section area, however, smooths the moments over the column's region. The qualitative results of this model are analogous to the negative moments smoothed on the supports of continuous beams. Besides, the quantitative results are little dependent on the mesh used, solving the singularity problem.

The Figure 26 shows the bending moments for Cases 4.1 / 4.2 / 4.3. When using the rigid section at column head to simulate the column dimensions, in case 4.1 , the maximum negative moment remains dependent on the mesh used (Figure 26).

However, modeling the column reaction distributed at the rigid sections gets the moments smoothed over the column cross-section and little dependent on the mesh used, as had occurred in the symmetrical structure (Figure 27).

The use of rigid section at column head results bigger bending moments than compared with models without rigid sections, and there is also a perturbation of moments within de column cross-section.

The Figure 28 shows the distribution of bending moments only over the column P5 region for Cases 3.1 / 3.2 / 3.3 and 4.1 / 4.2 / 4.3.

It can be noticed, once again, that the modeling cases with rigid sections provide moments more consistent when analyzed in the beginning of the rigid section or at the column face, and even Case 4.1 provides good results in these regions.

\section{Figure 18 - Symmetrical flat slab results - Column as pinned support - a - mesh 12,5 x 12,5; b- mesh 25 × 25;c-mesh 50 × 50; d-mesh 100 × 100 - (PUEL (7))}
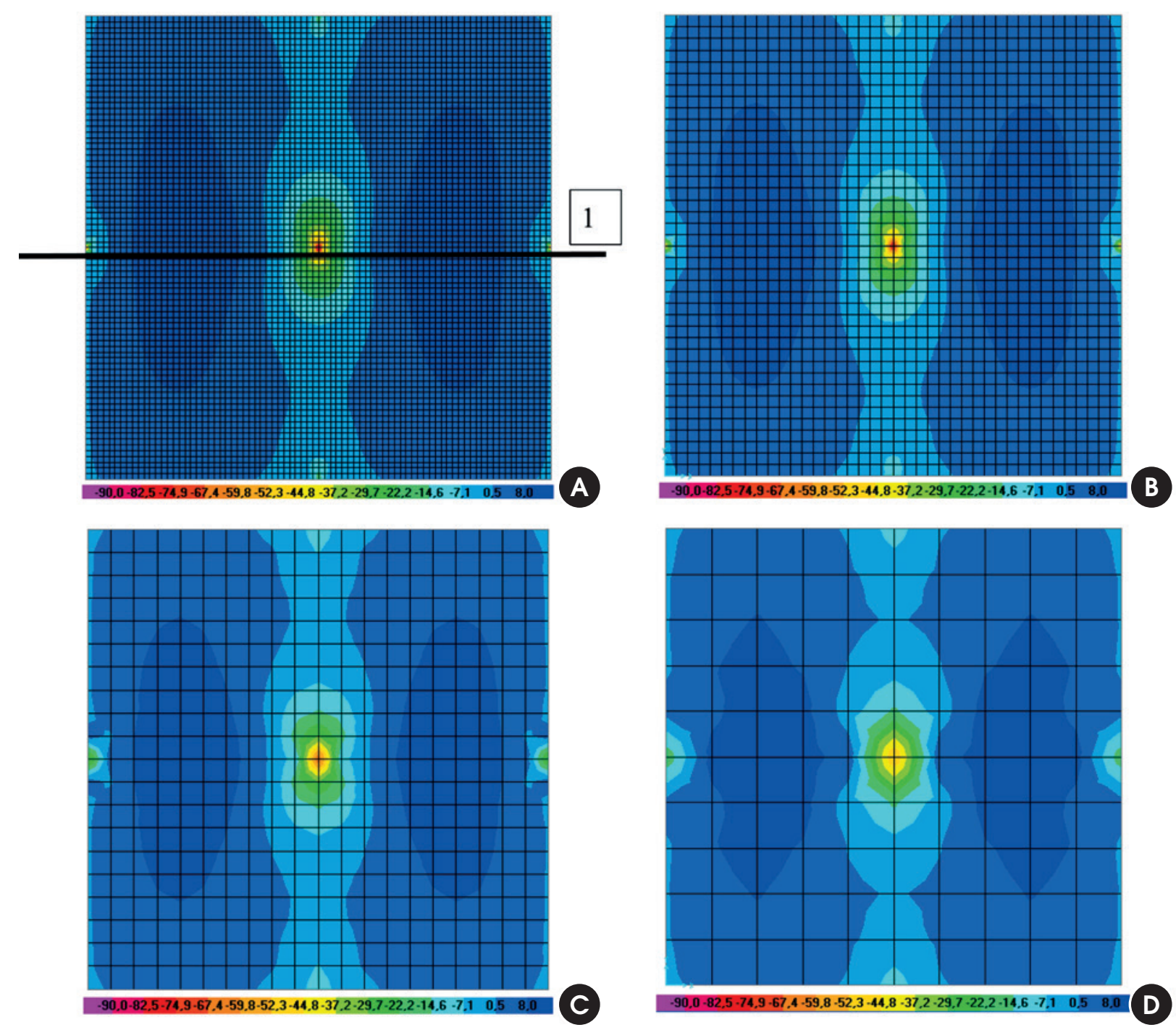
When there is asymmetry on the column position, the loading diagram of the column reaction is not uniform and, therefore, the maximum negative moment to the slab does not occur in the column center, as can be observed in Cases 1.2 and 1.3. The moments diagram gets moved in the opposite direction to the column joint spin.
Figure 29 and Figure 30 show the bending moments at the left and right sides of the column $\mathrm{P} 5$, respectively.

Except with mesh of $25 \times 25 \mathrm{~cm}$, the moments in both faces of the column P5 are about the same for the Cases 3.2 and 3.3, 4.1 and 4.2. The Case 4.3 showed results noticeably greater than the Cases cited above.

Figure 19 - Bending moments - Section 1 - symmetrical flat slab

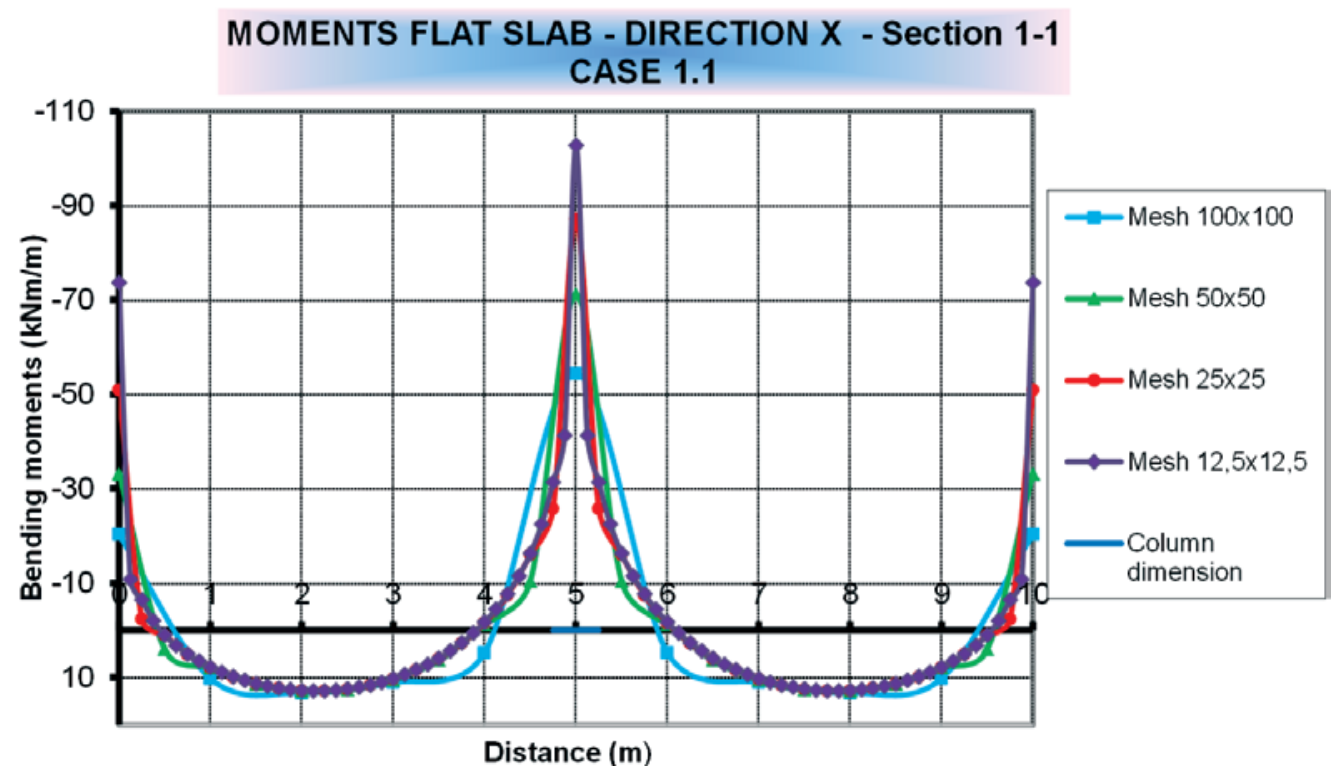

Figure 20 - Bending moments - Region column P5 - Cases 1.1/1.2/1.3/2.1/ 2.2/ 2.3

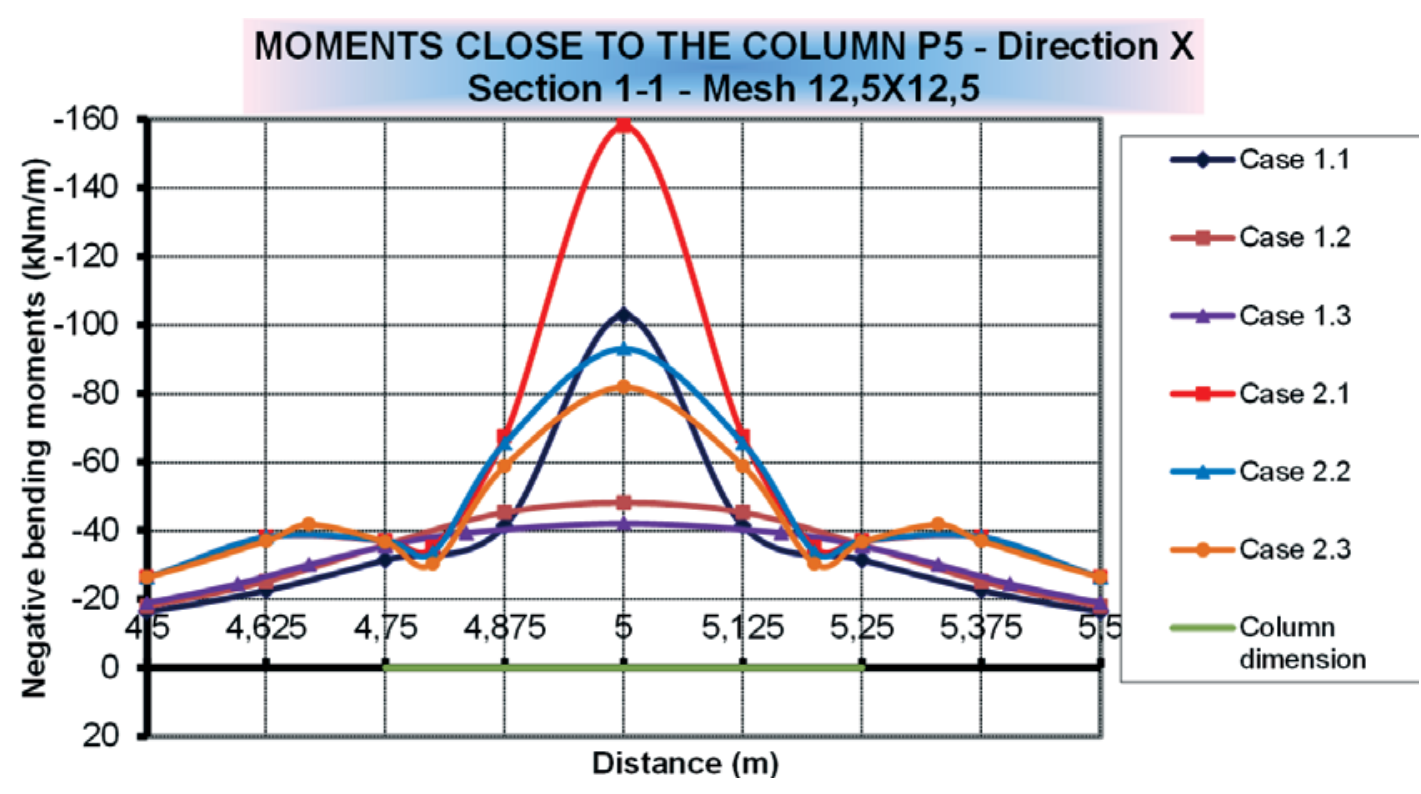


The Case 4.1, although has the problem of the singularity, the moments on both sides were consistent. This does not happen in Case 3.1, which also has the singularity problem, but without rigid section on the column head.

Besides the analyses of slab bending moments, which is inter- est to the slabs design, analyzing the column bending moments can be of interest, which will later be used for punching check and column design.

The Figure 31 shows the bending moments at the column P5 for Cases 3 and 4 .

Figure 21 - Bending moments over column P5 - Cases 1.1/1.2/1.3

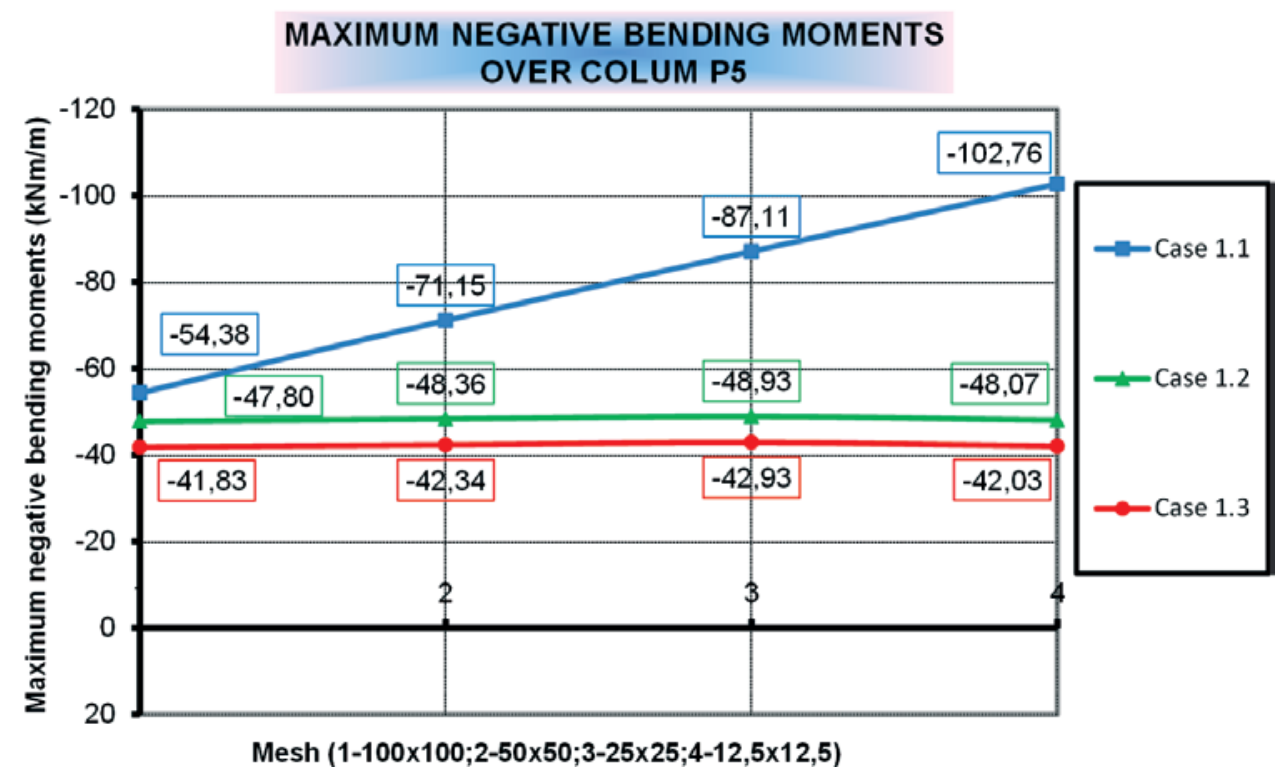

Figure 22 - Bending moments - face of column P5 - Cases 2.1/2.2/2.3

NEGATIVE BENDING MOMENTS - FACE OF COLUMN P5

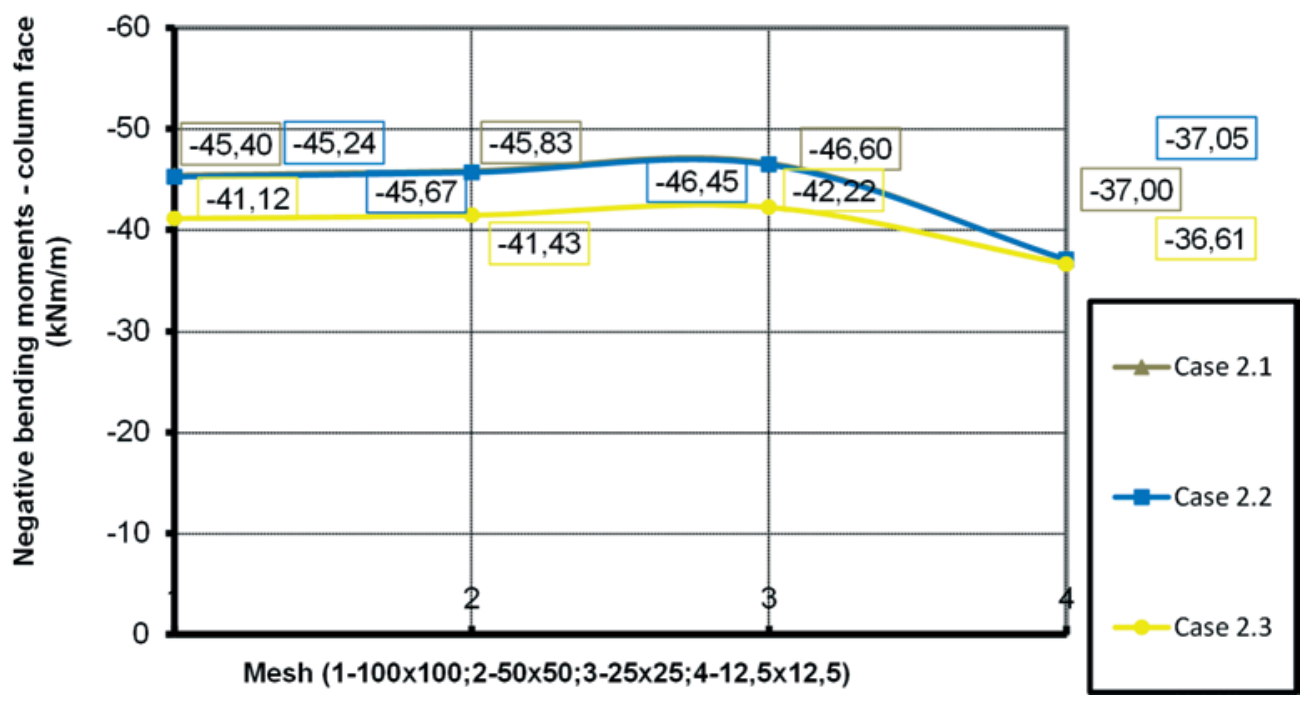


Numerical analysis of symmetrical and asymmetrical reinforced concrete flat slabs - an integrated slab/column analysis

In general, the bending moments at the column P5 for Case 4 were greater than those obtained for Case 3, on average $10 \%$ higher. The Cases 3.3 and 4.3 resulted in moments higher when compared with the Cases 3.2 and 4.2 , respectively. The difference to the mesh of $3,125 \times 3,125 \mathrm{~cm}$ was $8.0 \%$ of Case 3.3 compared to Case 3.2 and $3.0 \%$ of Case 4.3 compared to Case 4.2. Therefore, the models with rigid section at column head lead to minor differences when distributing the column reaction in the cross-section area than the cross-section area column projected at the geometric center of the slab.

Comparing the Cases 3.2 and 3.3 with 3.1 and the Cases 4.2 and 4.3 with 4.1 , it can be noticed that the Case 4.1 , although having the singularity problem, the column P5 moments are not very different from Cases 4.2 and 4.3 , which does not happen in Case 3 . The rigid section at column head allows adequately model the column stiffness, also observed by ROMBACH [10] (Case "e" Figure 3).

\section{3D Graphics}

With computer graphics booming, it's possible to explore the 3D features in viewing results. In this article in particular, as there are regions with significant concentration stress, the $3 \mathrm{D}$ views allow a better understanding in these regions behavior as well as the use of graphics resources to obtain sections of interest.

This type of visualization, often used in image processing, is much better than $2 \mathrm{D}$ views.

Thus, 3D graphics will be generated from the data obtained from linear analysis with the help of the following software:

- ArcGis/ArcMap [5]: software used for image processing;

Figure 23 - Asymmetrical flat slab results - Case 3.1 (PUEL (7))
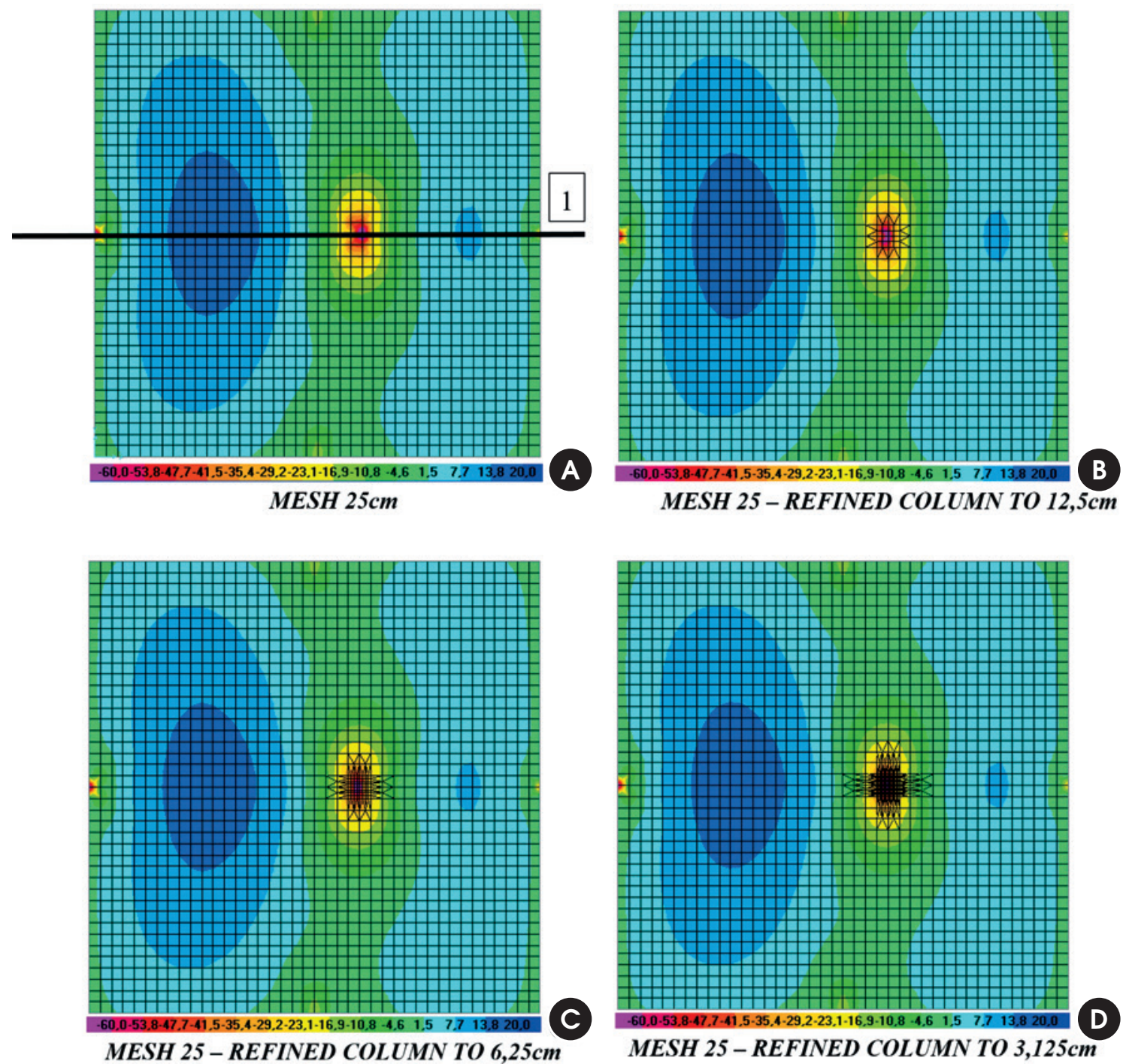
Global Mapper [6]: software used to render the triangulation. From the models generated in software SAP 2000 [4] for Case 3, exportsed to the $\mathrm{X}, \mathrm{Y}$ and $\mathrm{Z}$ mesh joints coordinates and imported for the software ArcGIS / ArcMap [5] and Global Mapper [6] . The $X$ and $Y$ coordinates giving the joint position in plant. The coordinate $Z$ represents the bending moment at each joint mesh. The final product is an Rastes image with pixels of $0.04 \mathrm{~cm}$, generated from points arranged according actual values.

In order to understand the region where the stress concentration

Figure 24 - Bending moments - Asymmetrical flat slab - Section 1 - Cases 3.1/ 3.2/ 3.3

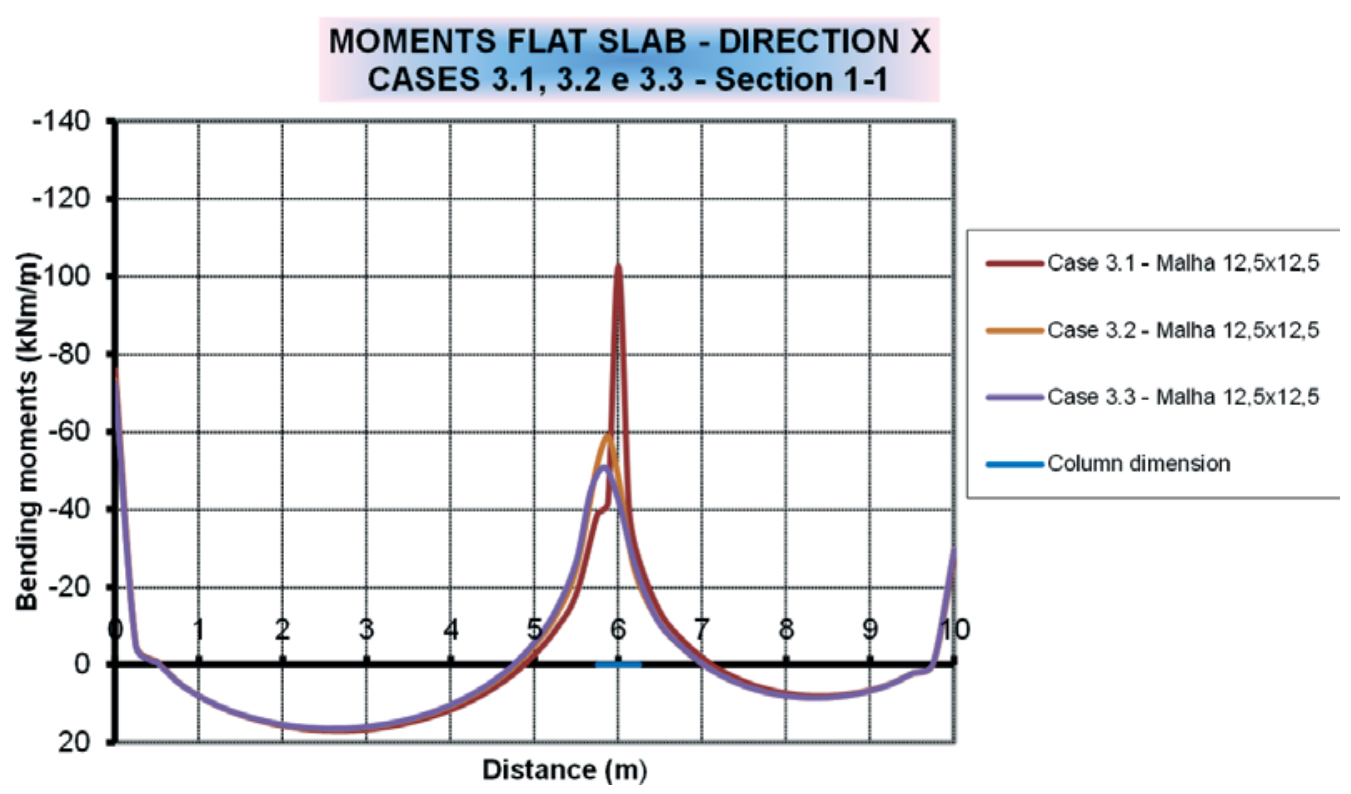

Figure 25 - Maximum negative bending moments over column P5

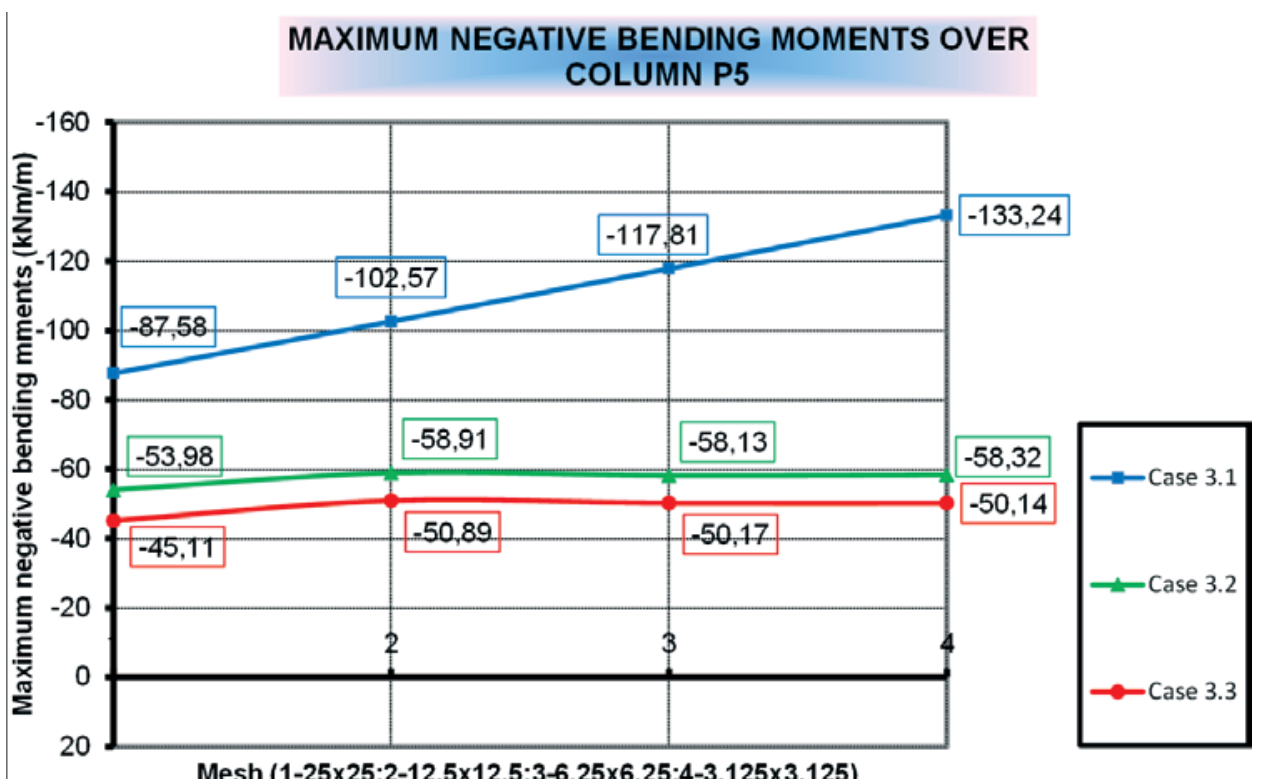


occurs, it shows the 3D display bending moments. The graphics will be presented to the Cases 3.1, 3.2 and 3.3 (the column region without rigid section with asymmetry 1 meter), considering the mesh of $25 \times 25 \mathrm{~cm}$, with transition in the column region to $12,5 \times 12,5 \mathrm{~cm}$. In all cases a section was made in the slab (Figure 32 ), which pass through the column P5 center (Section 1).

The points shown in Figure 32 coincide with the mesh joints used in the SAP 2000 [4] for the cases studied in this article. The Figure 32 refers to mesh of $25 \times 25 \mathrm{~cm}$ with transition on column region to $12,5 \times 12,5 \mathrm{~cm}$.

Figure 26 - Bending moments - Asymmetrical flat slab - Section 1 - Cases 4.1/ 4.2/ 4.3

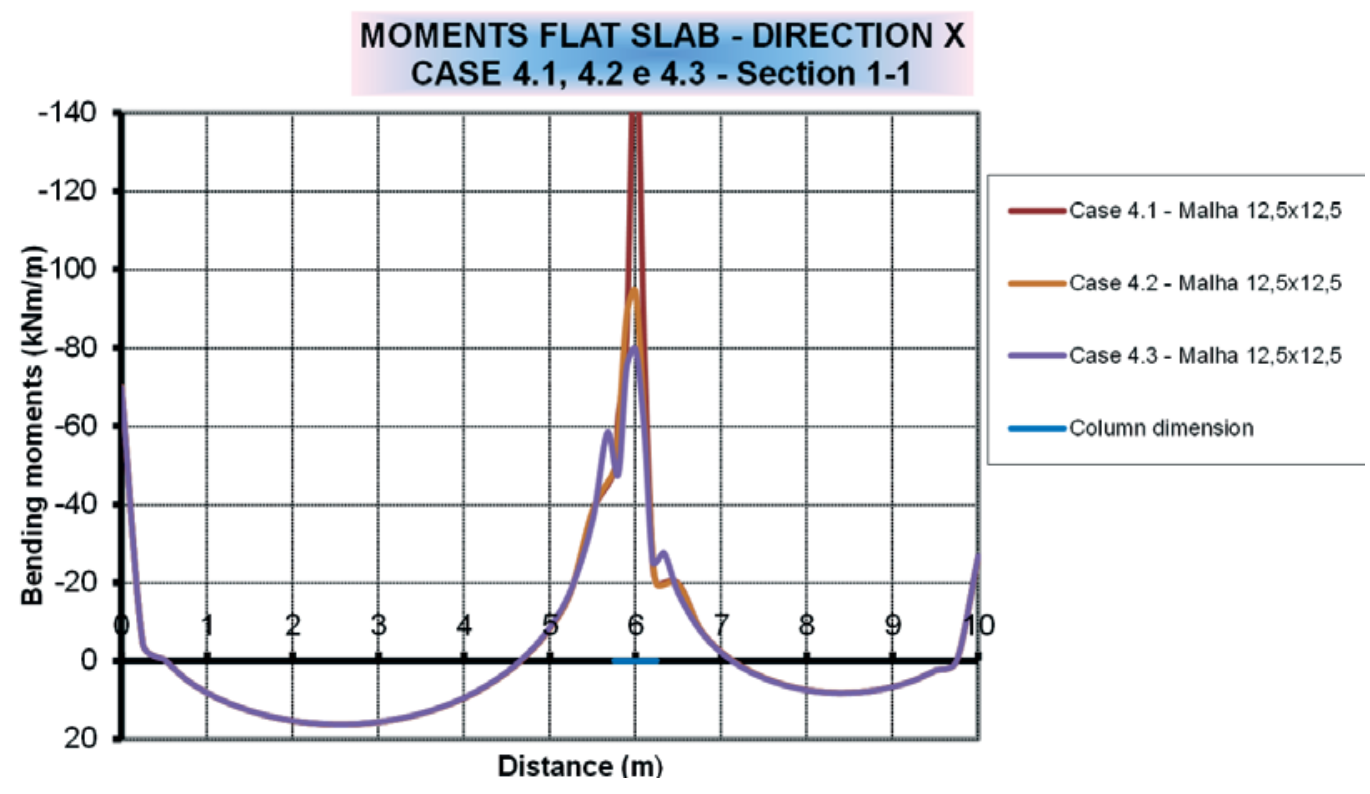

Figure 27 - Bending moments - Asymmetrical flat slab - Section 1 - Case 4.2

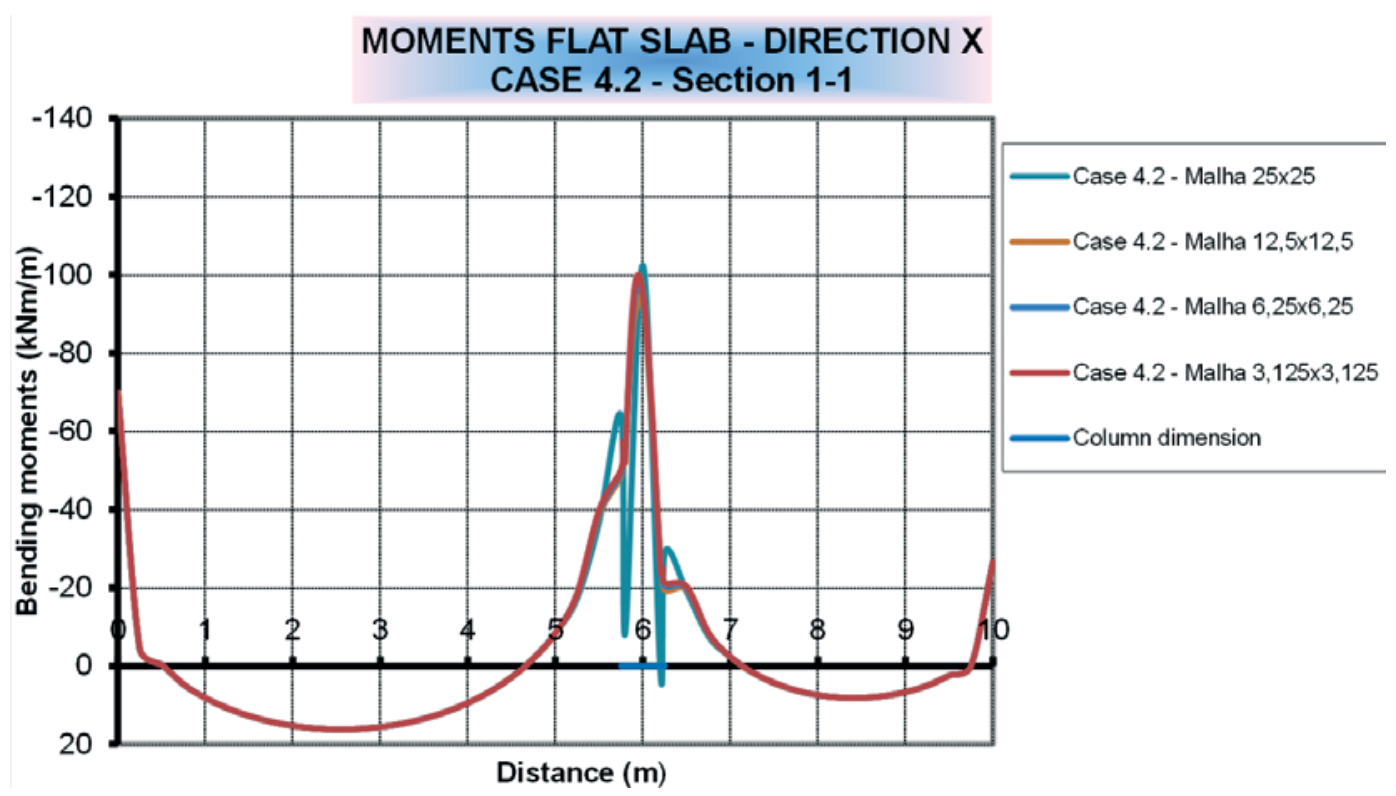


The Figure 33 shows the 3D display of the moments in the direction $\mathrm{X}$, for Case 3.1, Figure 33a without rendering and Figure 33b with rendering.

The Figure 34 shows the section 1 to Case 3.1 .

The Figure 35 shows the 3D display of the moments in the direc- tion X, for Case 3.2, Figure 35a without rendering and Figure 35b with rendering.

The Figure 36 shows the section 1 to Case 3.2 .

The Figure 37 shows the 3D display of the moments in the direction $\mathrm{X}$, for Case 3.3, Figure $37 \mathrm{a}$ without rendering and

Figure 28 - Bending moments - Region Column P5 - Cases 3.1/3.2/3.3/4.1/4.2/4.3

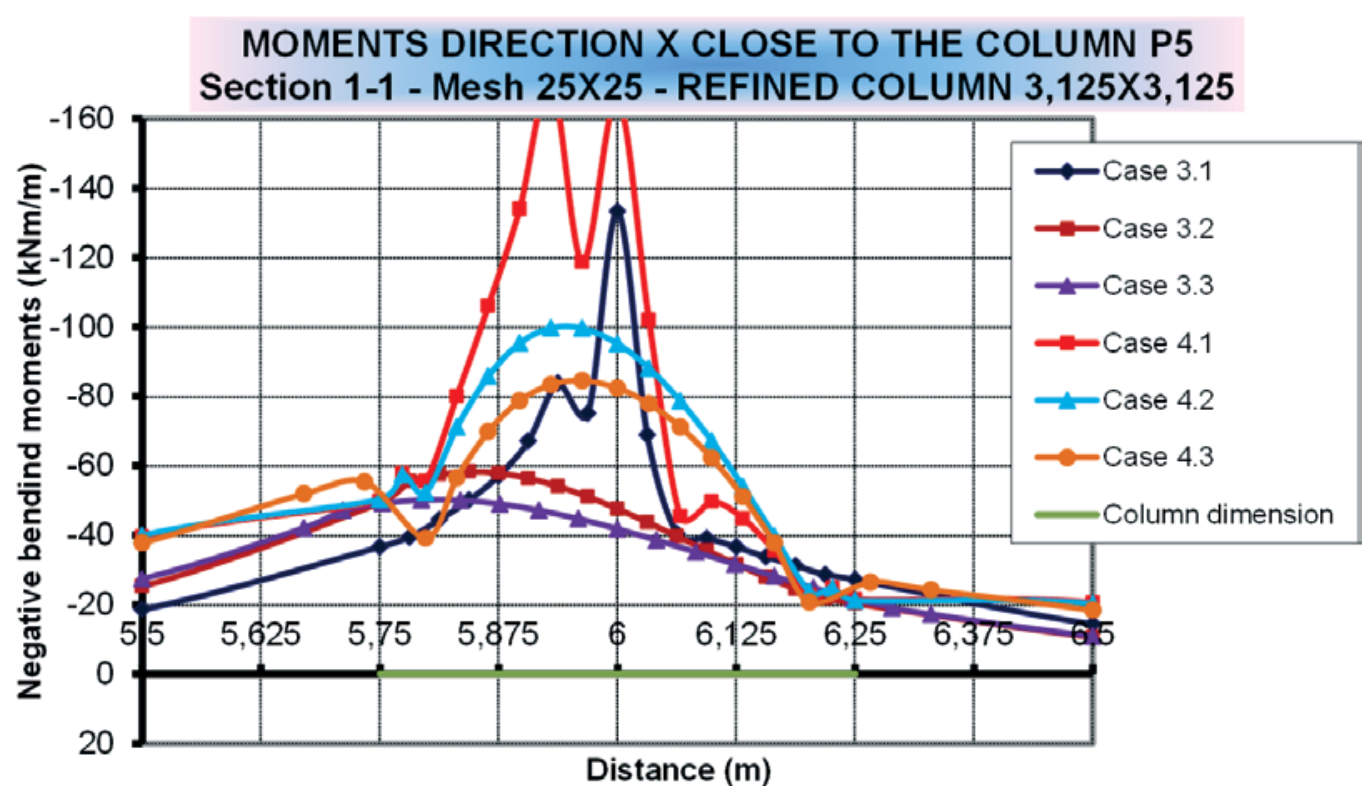

Figure 29 - Maximum negative bending moments - Left face column P5

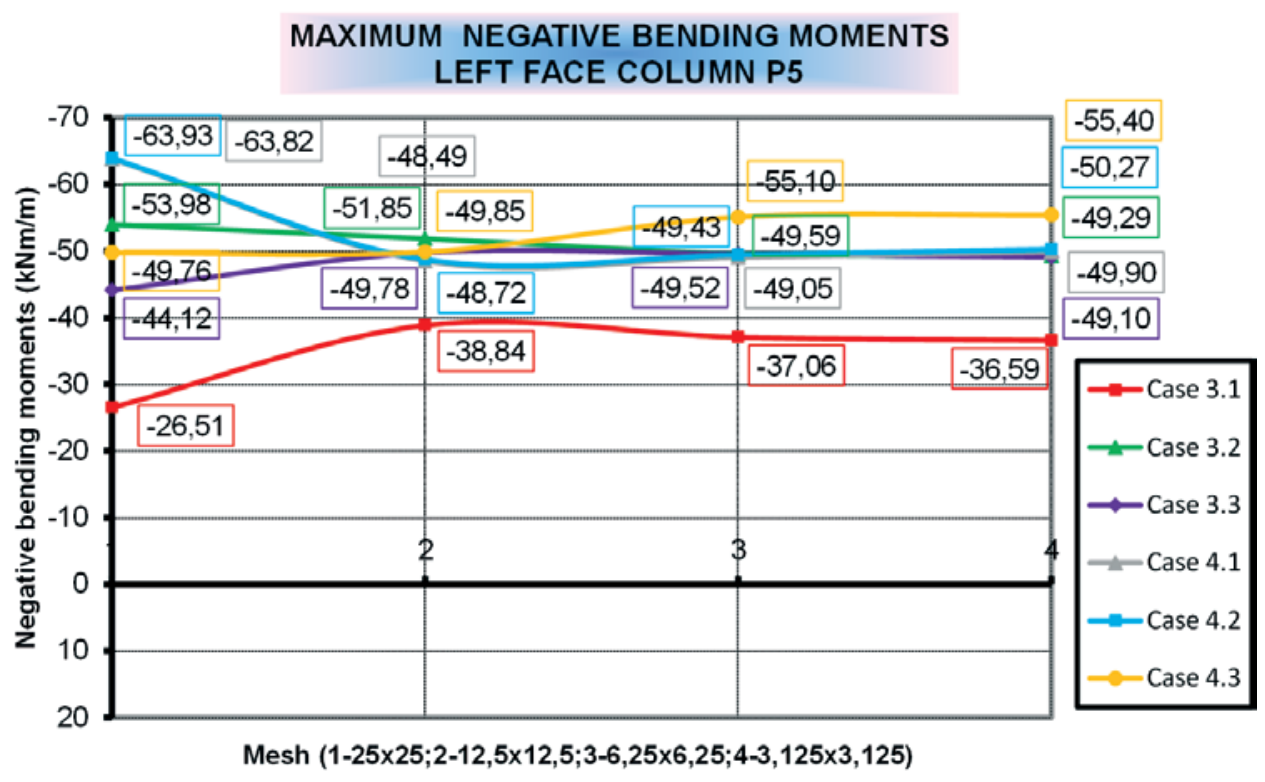


Figure $37 \mathrm{~b}$ with rendering.

The Figure 38 shows the section 1 to Case 3.3.

The $3 \mathrm{D}$ view allows the visualization of the bending moments along the all slab, facilitating detailed analysis of their behavior in the vicinity column region. The results before have allowed a quick visualization of large stress concentrations in the column region, and its possible see that the reaction distribution gets smoothed the bending moments.

The use of GIS software allows, besides to obtaining predetermined cross sections, future postprocessing to obtain areas of

Figure 30 - Maximum negative bending moments - Right face column P5 RIGHT FACE COLUMN P5

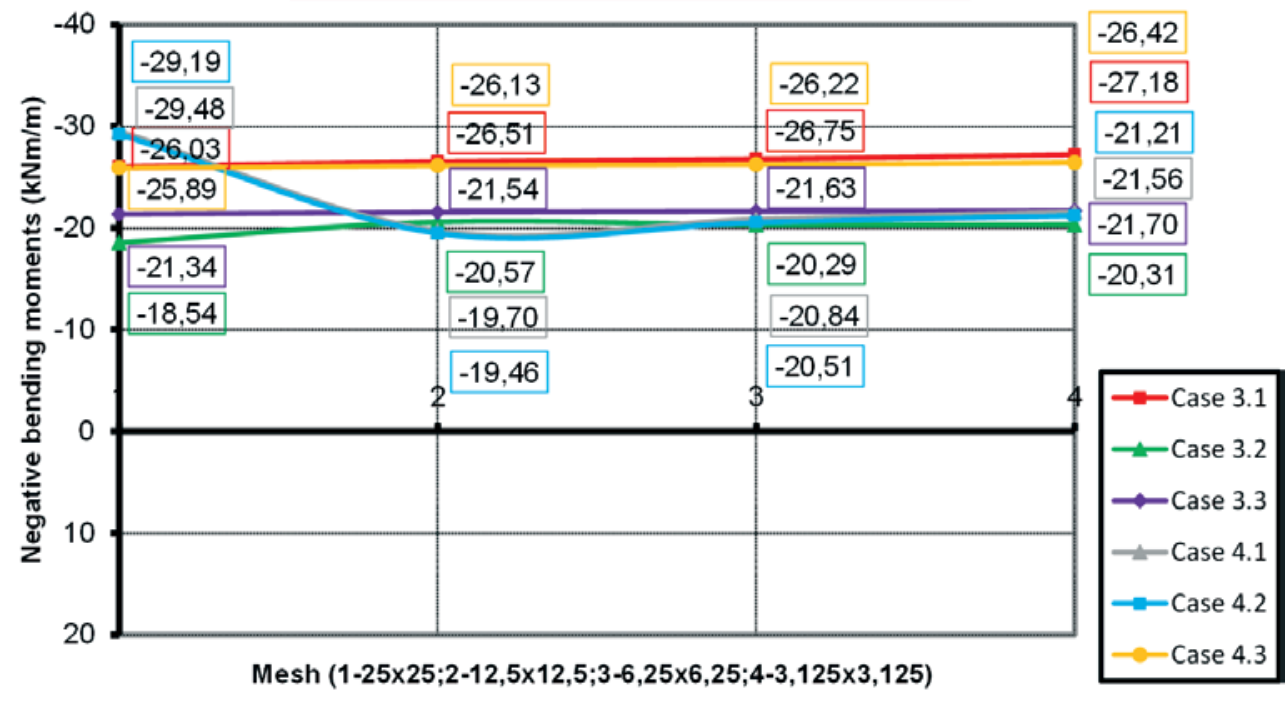

Figure 31 - Bending moment at the column P5 - Asymmetrical flat slab

BENDING MOMENTS AT THE COLUMN P5

FINITE ELEMENT METHOD (FEM)

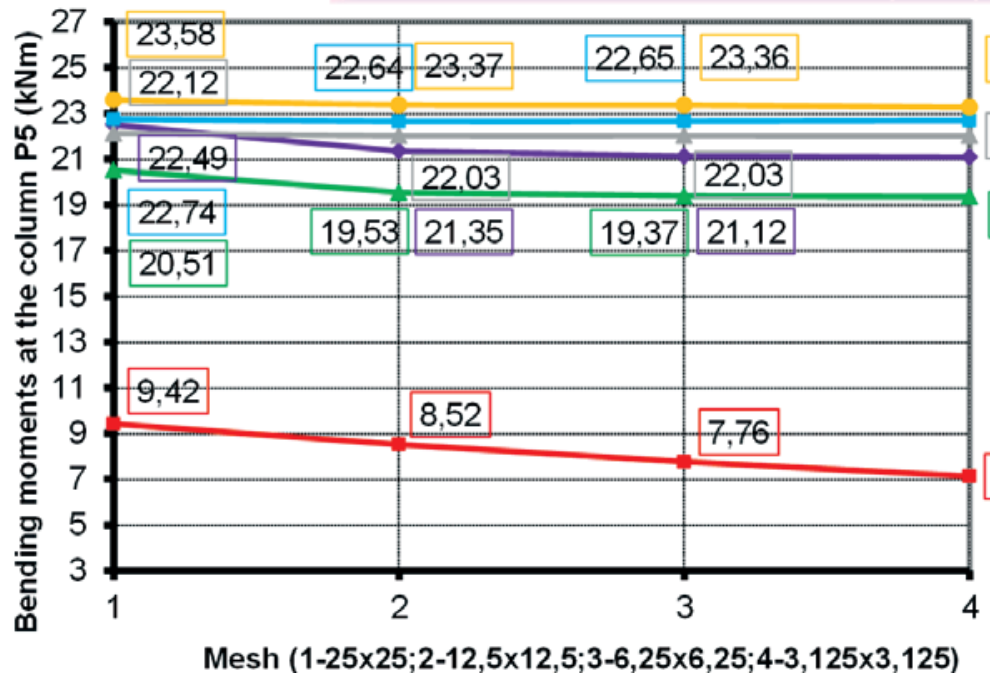

$23,2722,68$

$22,02 \quad 21,08$

19,35

7,13

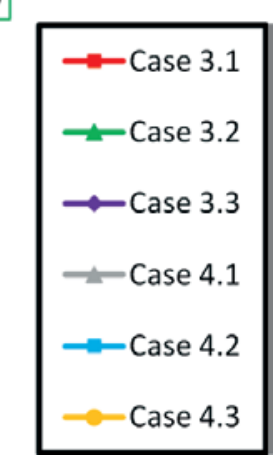


these sections, which in this case correspond to moments resulting slab sections. These tools may be important for defining criteria for the design of slab cross sections.

\section{Conclusions}

The elastic-linear analysis of structures studied showed the use of suitable modeling to the column $x$ slab connections. The procedure proposed in this work, distributing the column reaction as a distributed load, was efficient and can be applied easily even in commercial structural analysis programs.

The modeling used solve the singularity problem can be applied in both symmetric and asymmetric structures, and it was little sensitive to the mesh variation after a suitable refinement.

The results obtained with the bending moments smoothed over the column allowed an easy understanding of the phenomenon on P5 region, facilitating future decisions to use these results.

The column reaction distributed on the slab in the column crosssection and also the reaction distributed in the column region projected at the geometric center of the slab, provided a small change in the maximum moment value, and the distribution projected at the geometric center of the slab decreased a little this value, going towards results when models with rigid section at the head column. The use of rigid sections at the column head could include in the model, the stiffness column effect in this region. The distributed load inclusion provided the best quality results within the column area. However, the values closer to the column face are best suited to represent the efforts in this region.

When analyzing a model column $\mathrm{x}$ slab integrated, in addition to efforts on the slab may be necessary to study the efforts on the columns for punching check and column design.

While the column P5 axial forces in models with or without rigid section, distributing or not the column reaction as loading the slab, present results with little variation between themselves, the bend-

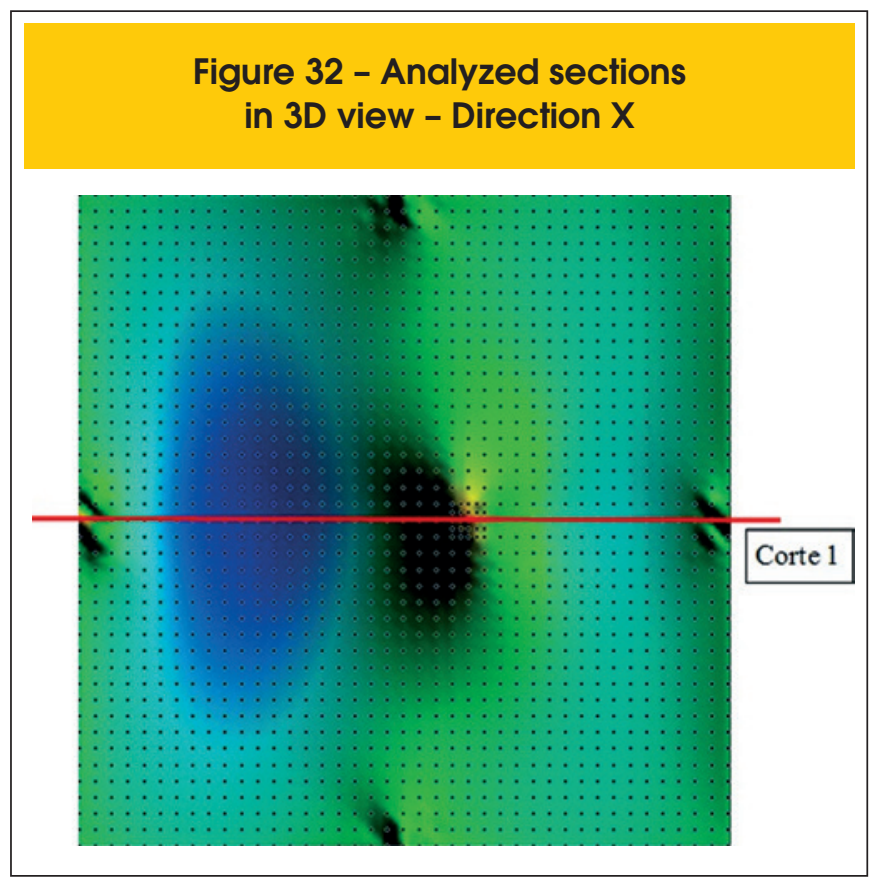

ing moments depends on the modeling. When it models the column as pinned support and does not consider the rigid section at the column head (Case 3.1), the results were much smaller for refined mesh within column P5 region. This occur due a lot of elements within the column with small stiffness, damaging the slabs-columns connection. These models must be avoided. However, when distributing the P5 column reaction at the column cross-section area, keeping the column region without rigid sections, the bending moment in column P5 was low sensitive to the mesh used in both analyzes and numerically much greater than values obtained in Case

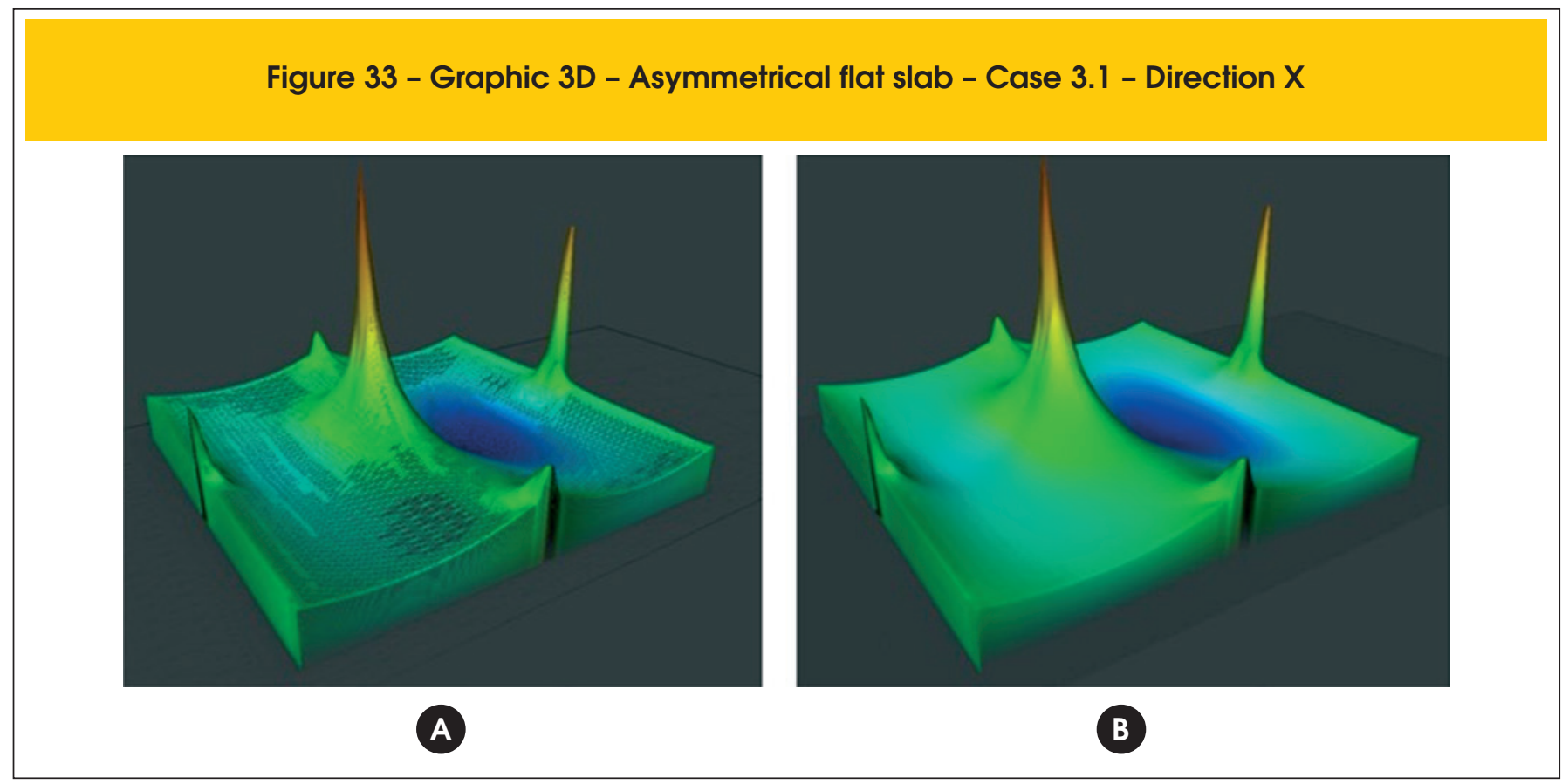


3.1. When use rigid sections at the column head, in all subcases of the Case 4, the bending moment at the column are close to each other, and numerically great than those obtained in the Cases 3.2 and 3.3. By adding rigid elements on the column P5 area made the slab-column connection present a behavior that takes into account the correctly stiffness of this connection, as showed in Case 4.1: even with the singularity problem, the bending moment at the column P5 showed good results, being also a possible solution. Finally, the bending moments displayed in the slab in 3D graphics with the help of specialized software for GIS promotes the analysis results. It's possible to view the bending moments in a spatial form, in all directions. This type of resource may to be important in defining criteria for the slab design.

\section{Acknowledgements}

The authors wish to express sincere thanks to the company GeoEnergy Engenharia Ltda for providing the computational

Figure 34 - Section 1 - Asymmetrical flat slab - Case 3.1 - Direction X

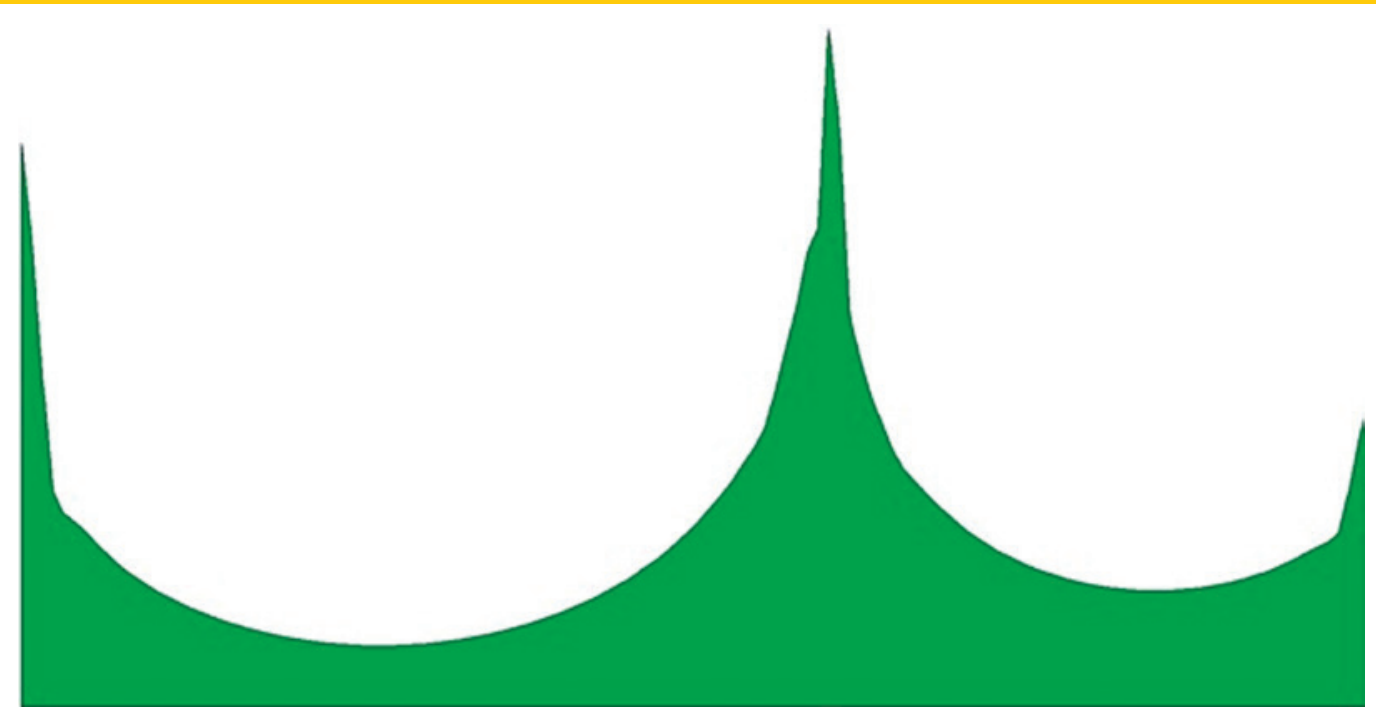

Figure 35 - Graphic 3D - Asymmetrical flat slab - Case 3.2 - Direction X

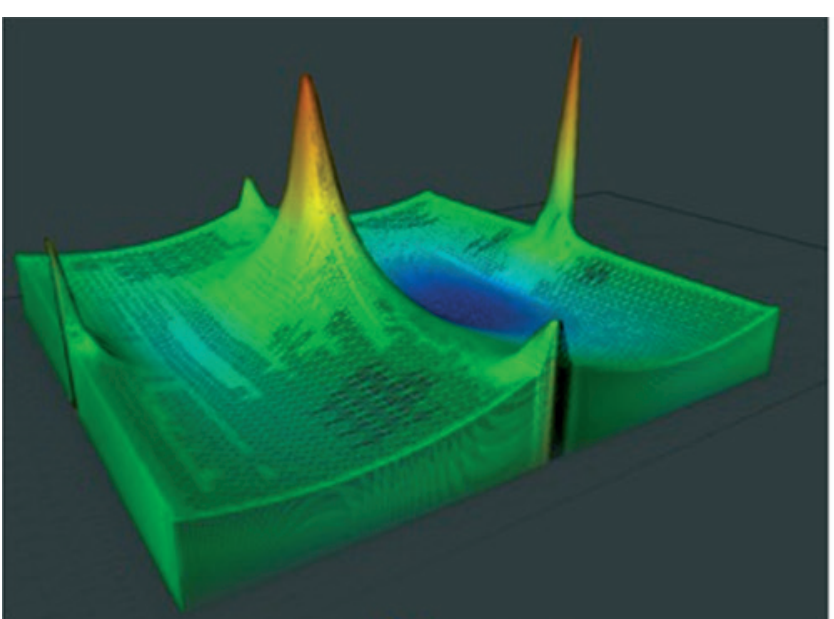

A

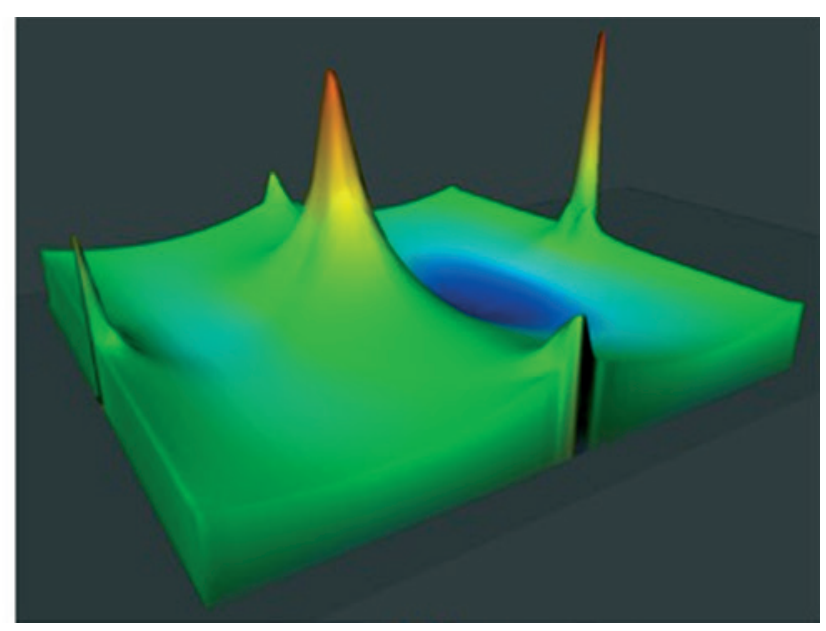

B 
geoprocessing programs necessary for the development of this work.

\section{References}

[1] SKORPEN S. A. \& DEKKER N. W. The application and interpretation of liner finite element analysis results in the design and detailing of hogging moment regions in reinforced concrete flat slaps. Technical Paper. Journal of the South African Institution of Civil Engineering. South African, 2014.
[2] CHOI K. K. \& KIM J.C., Nonlinear model simulating loaddefornation relationship of flat plate structures. Technical Paper. Engineering Structures. South Korea, 2014.

[3] MURRAY K.A. \& CLELAND D.J. \& GILBERT S. The Development of a non-linear numerical model to simulate the behaviour of reinforced concrete flat slabs in the vicinity of edge columns. Technical Paper. Construction and Building Materials. Belfast, 2005.

[4] Computers and Structures, Inc. SAP 2000 - Integrated

\section{Figure 36 - Section 1 - Asymmetrical flat slab - Case 3.2 - Direction X}

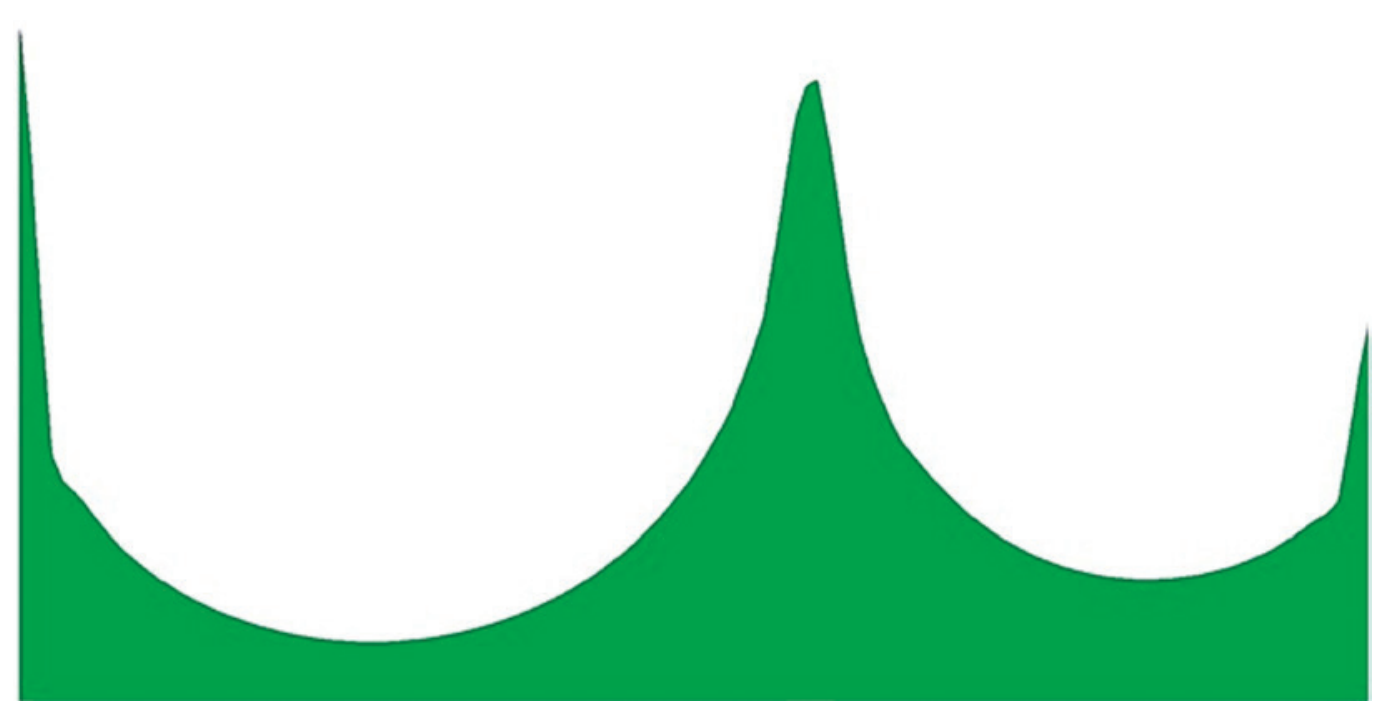

Figure 37 - Graphic 3D - Asymmetrical flat slab - Case 3.3 - Direction X

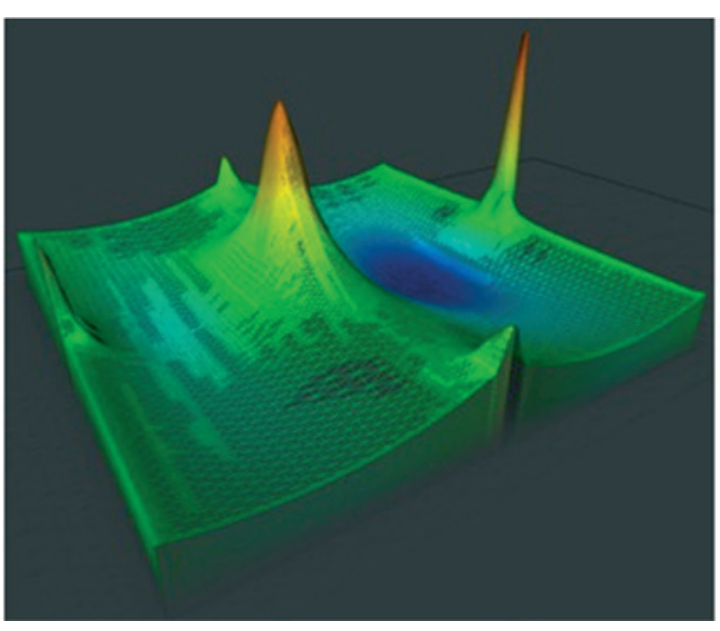

A

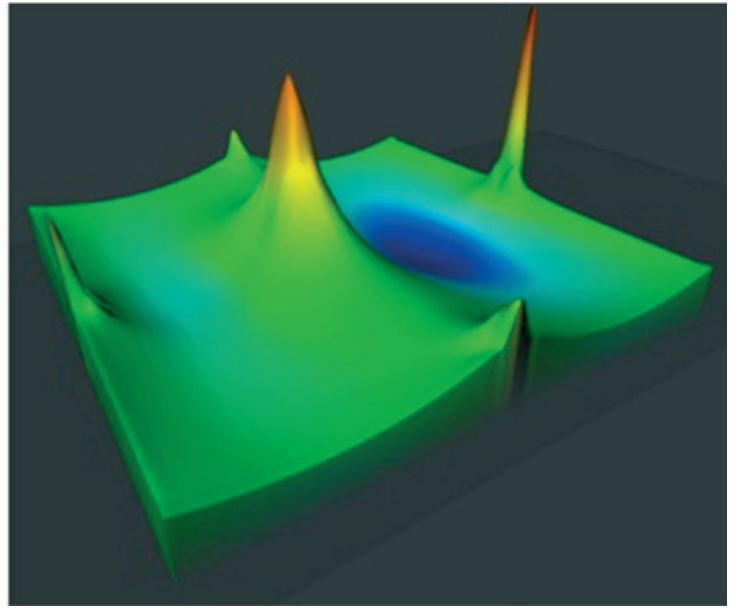

B 


\section{Figure 38 - Section 1 - Asymmetrical flat slab - Case 3.3 - Direction X}

Software for Structural Analysis and Design. Version 11. USA, 2008.

[5] ArcGis/ArcMap, ESRI - suite of geospatial processing programs, and is used primarily to view, edit, create, and analyze geospatial data. Version , 10.2.2. USA, 2013

[6] Global Mapper, Blue Marble Geographics - Handles both vector, raster, and elevation data, and provides viewing, conversion, and other general GIS features. Version 16.1. USA, 2013.

[7] PUEL, André. Modelagem de lajes planas simétricas e assimétricas em concreto armado - Análise integrada laje $\mathrm{x}$ pilar. Dissertação de Mestrado. Programa de Pós-Graduação em Engenharia Civil, Universidade Federal de Santa Catarina, 2009. 152 páginas.

[8] ASSOCIAÇÃO BRASILEIRA DE NORMAS TÉCNICAS. NBR 6118:2014 - Projeto de Estruturas de Concreto - Procedimentos. Rio de Janeiro, 2014.
[9] EUROCODE 2 2003. BS EN 1992-1-1:2003. Design of concrete structures. Part 1-1: General - Rules and rules for buildings. Brussels: European Committee for Standardisation.

[10] ROMBACH, G A. Finite element design of concrete structures. London: Thomas Telford, 2004.

[11] GLÓRIA, Rodrigo Luz. Estudo do Dimensionamento de Vigas na Ligação com Pilares em Projeto de Estruturas de Concreto, Dissertação de Mestrado. UFSC. Florianópolis, 2003. 113 páginas.

[12] HENNRICHS, Carlos A., Estudo sobre a modelagem de lajes planas de concreto armado, Dissertação de Mestrado. UFSC. Florianópolis, 2003.

[13] PEDROZO, David Guillermo Esteche. Análise Crítica dos Critérios de Projeto de Lajes Protendidas. Dissertação de mestrado. UFSC. Florianópolis, 2008. 